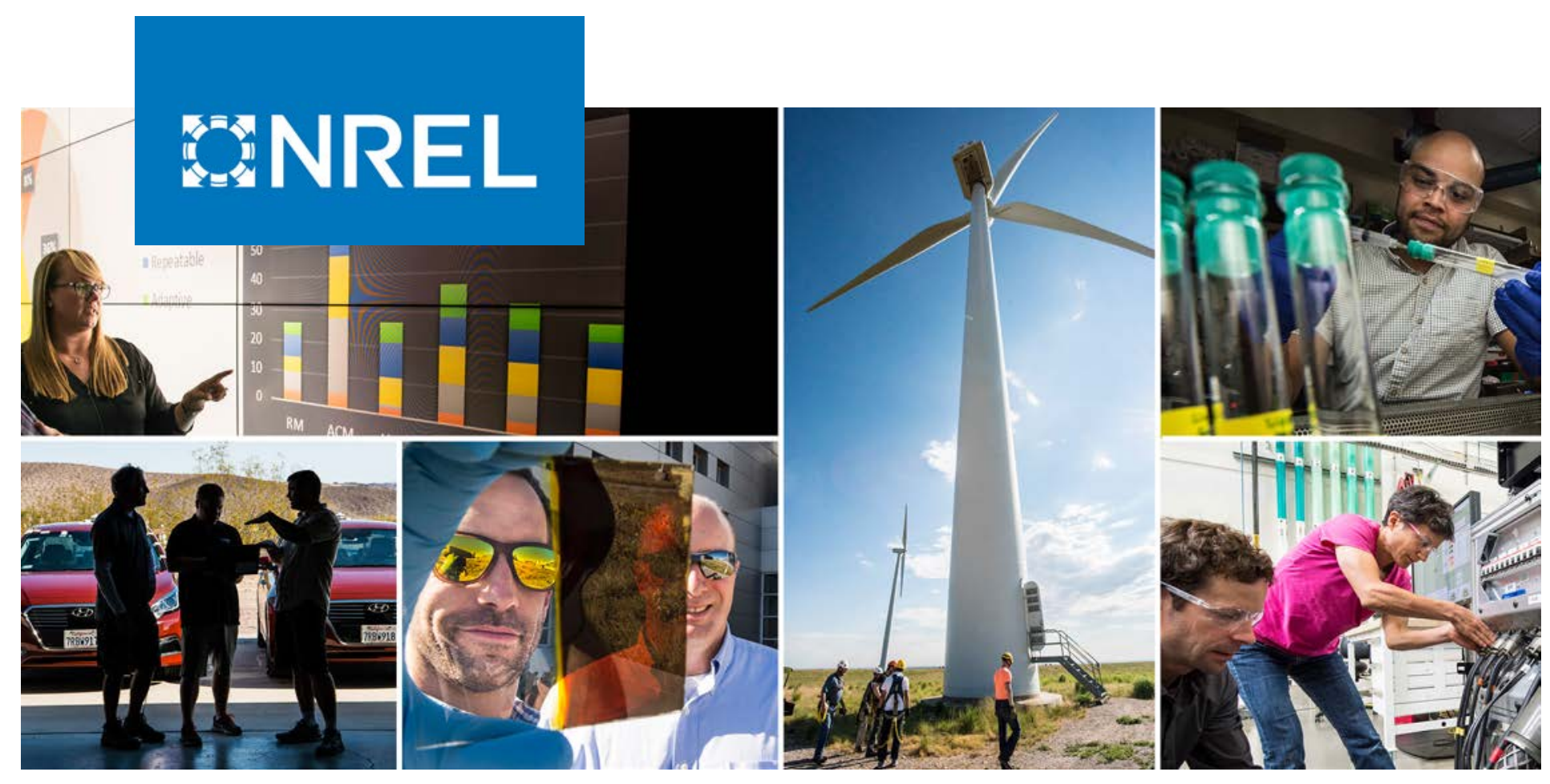

\title{
Community Choice Aggregation: Challenges, Opportunities, and Impacts on Renewable Energy Markets
}

Eric O'Shaughnessy, ${ }^{1}$ Jenny Heeter, ${ }^{1}$ Julien Gattaciecca, ${ }^{2}$ Jenny Sauer, ${ }^{1}$ Kelly Trumbull, ${ }^{2}$ and Emily Chen ${ }^{1}$

1 National Renewable Energy Laboratory

2 Luskin Center for Innovation, University of California, Los Angeles

NREL is a national laboratory of the U.S. Department of Energy Office of Energy Efficiency \& Renewable Energy

Operated by the Alliance for Sustainable Energy, LLC

This report is available at no cost from the National Renewable Energy Laboratory (NREL) at www.nrel.gov/publications.
Technical Report

NREL/TP-6A20-72195

February 2019 


\section{GNREL}

\section{Community Choice Aggregation: Challenges, Opportunities, and Impacts on Renewable Energy Markets}

Eric O'Shaughnessy, ${ }^{1}$ Jenny Heeter, ${ }^{1}$ Julien Gattaciecca, ${ }^{2}$ Jenny Sauer, ${ }^{1}$ Kelly Trumbull, ${ }^{2}$ and Emily Chen ${ }^{1}$

1 National Renewable Energy Laboratory

2 Luskin Center for Innovation, University of California, Los Angeles

\section{Suggested Citation}

O'Shaughnessy, Eric, Jenny Heeter, Julien Gattaciecca, Jenny Sauer, Kelly Trumbull, and Emily Chen. 2019. Community Choice Aggregation: Challenges, Opportunities, and Impacts on Renewable Energy Markets. Golden, CO: National Renewable Energy Laboratory. NREL/TP-6A20-72195. https://www.nrel.gov/docs/fy19osti/72195.pdf.

NREL is a national laboratory of the U.S. Department of Energy Office of Energy Efficiency \& Renewable Energy Operated by the Alliance for Sustainable Energy, LLC

This report is available at no cost from the National Renewable Energy Laboratory (NREL) at www.nrel.gov/publications.

Contract No. DE-AC36-08GO28308
Technical Report NREL/TP-6A20-72195

February 2019

National Renewable Energy Laboratory 15013 Denver West Parkway Golden, CO 80401 303-275-3000 • www.nrel.gov 


\section{NOTICE}

This work was authored in part by the National Renewable Energy Laboratory, operated by Alliance for Sustainable Energy, LLC, for the U.S. Department of Energy (DOE) under Contract No. DE-AC36-08GO28308. Funding provided by U.S. Department of Energy Office of Energy Efficiency and Renewable Energy Solar Energy Technologies Office. The views expressed in the article do not necessarily represent the views of the DOE or the U.S. Government.

This report is available at no cost from the National Renewable Energy Laboratory (NREL) at www.nrel.gov/publications.

U.S. Department of Energy (DOE) reports produced after 1991 and a growing number of pre-1991 documents are available free via www.OSTI.gov.

Cover Photos by Dennis Schroeder: (clockwise, left to right) NREL 51934, NREL 45897, NREL 42160, NREL 45891, NREL 48097, NREL 46526.

NREL prints on paper that contains recycled content. 


\section{Acknowledgments}

This work was supported by the Solar Energy Technologies Office at the U.S. Department of Energy. The authors would like to thank the following individuals and organizations for their thoughtful review of this work: J.R. DeShazo (Luskin Center for Innovation, University of California Los Angeles), Rachel Henderson (Smart Electric Power Alliance), Trieu Mai (NREL), Shawn Marshall (LEAN Energy U.S.), and Jennifer Spinosi (CleanChoice Energy). The authors would like to thank the following individuals and their companies for participating in interviews to inform this study: Denise Allard (Colonial Power Group), Charlotte Binns (JouleCommunity Power), Yaima Braga (Green Energy Consumers Alliance), Austin Brandt (Cape Light Compact), Mark Cappadonna (Colonial Power Group), Brian Daniels (Rhode Island League of Cities and Towns), Anna Ebers (DOE), Deb Emerson (Sonoma Clean Power), Richard Engel (Redwood Coast Energy Authority), Erica Ferguson (Sonoma Clean Power), Michael Forrester (City of Cincinnati), Kyle Fricker (DOE), Katherine Hernandez (Pico Rivera Innovative Municipal Energy), Pamela Leonard (Silicon Valley Clean Energy), Dorian Moore (Vistra Energy), and Dan Welsh (Westchester Power). The authors would like to also Mike Meshek (NREL) for editorial support. 


\section{Executive Summary}

Community choice aggregations (CCAs) are local governmental entities that procure electricity on behalf of retail electricity customers within a certain geographic area (Figure ES-1). CCAs may be run directly by a city or county government or by a third party through a contractual arrangement such as a joint powers agreement. Often called a hybrid utility model, a CCA partners with local investor-owned utilities that continue to provide consolidated billing, transmission, and distribution of electric power to their shared customers. CCAs first emerged in the late 1990s as a few states began to pass legislation enabling electric aggregation. A key feature of the enabling legislation in eight states is that it allows CCAs to form such that the CCA becomes the default electricity provider and customers may opt out in order to return to utility service. The opt-out structure increases program participation relative to a voluntary "opt in" structure, meaning CCAs can aggregate relatively large customer bases, providing economies of scale and buying power in wholesale markets. The "choice" component of the term CCA reflects a key feature of aggregation: CCAs can choose the electric resources that supply their community and may choose to offer more renewable energy than the incumbent utility.

\section{COMMUNITY}

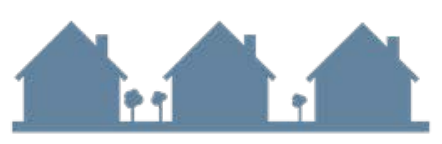

CCAs serve retail electricity customers within a given city, county, or group of jurisdictions.

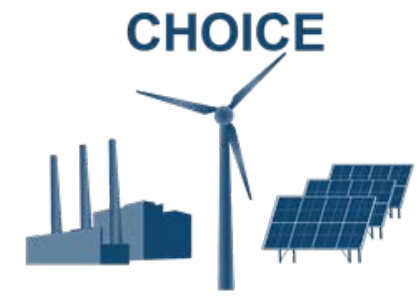

CCAs choose their own electricity portfolio, which may include renewable energy in excess of state RPS.
AGGREGATION

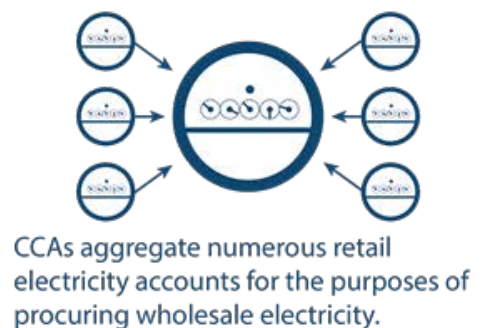

Figure ES-1. Community choice aggregation

In this report, we seek to summarize the status of CCAs in the United States. We quantify CCA sales and customer bases by aggregating publicly-available data and CCA survey data. We summarize trends in CCA electricity portfolios with a focus on renewable energy procurement. Based on 12 interviews with CCAs and other stakeholders, we identify key factors that could determine the impacts of CCAs on renewable energy markets. Lastly, we identify the challenges created and faced by the expansion of CCAs.

CCAs compose their electricity portfolios of numerous resources, including fossil fuel-based generators as well as generators of renewable energy. We estimate that about 750 CCAs procured about 42 million megawatt-hours (MWh) of electricity on behalf of about five million customers in 2017 in the eight states with CCA-enabling legislation: California, Illinois, Massachusetts, New Jersey, New York, Ohio, Rhode Island, and Virginia (though no CCAs are currently active in Virginia). All CCAs are required to procure enough renewable energy to comply with state renewable energy mandates, the same as other load-serving entities such as utilities. About 100 CCAs spread across California, Illinois, Massachusetts, New York, and Ohio procure more renewable energy than is required by these mandates. We refer to this "voluntary" portion of renewable energy as voluntary green power. We estimate that in 2017 CCAs procured about 8.9 million MWh of voluntary green power, representing about $21 \%$ of all CCA sales, on behalf of about 2.7 million customers. CCA-driven demand for voluntary green power could 
affect grid-wide electricity portfolios by increasing the amount of renewable energy generators on the grid. The expansion of CCAs could affect electricity portfolios in other ways if CCAs prefer specific resources, such as low-cost natural gas. These additional electricity portfolio impacts are outside the scope of this study but are an area for future research.

About 13\% of CCAs offer voluntary green power. Most CCAs formed primarily to reduce electricity costs on behalf of CCA customers. CCAs have emphasized voluntary green power to varying degrees in different states (Figure ES-2). In California, all active CCAs procure more renewable energy than required by state law. Furthermore, California CCAs have emphasized procurement of in-state renewable energy more than CCAs in other states, and some CCAs have signed long-term contracts for new renewable energy projects. In New York, about half of the sales of the only active CCA represent voluntary green power. Outside California and New York, with the exception of about 90 CCAs in Illinois, Massachusetts, and Ohio, most CCAs do not offer voluntary green power as their default electricity product. No CCAs in New Jersey or Rhode Island were procuring voluntary green power in 2017.

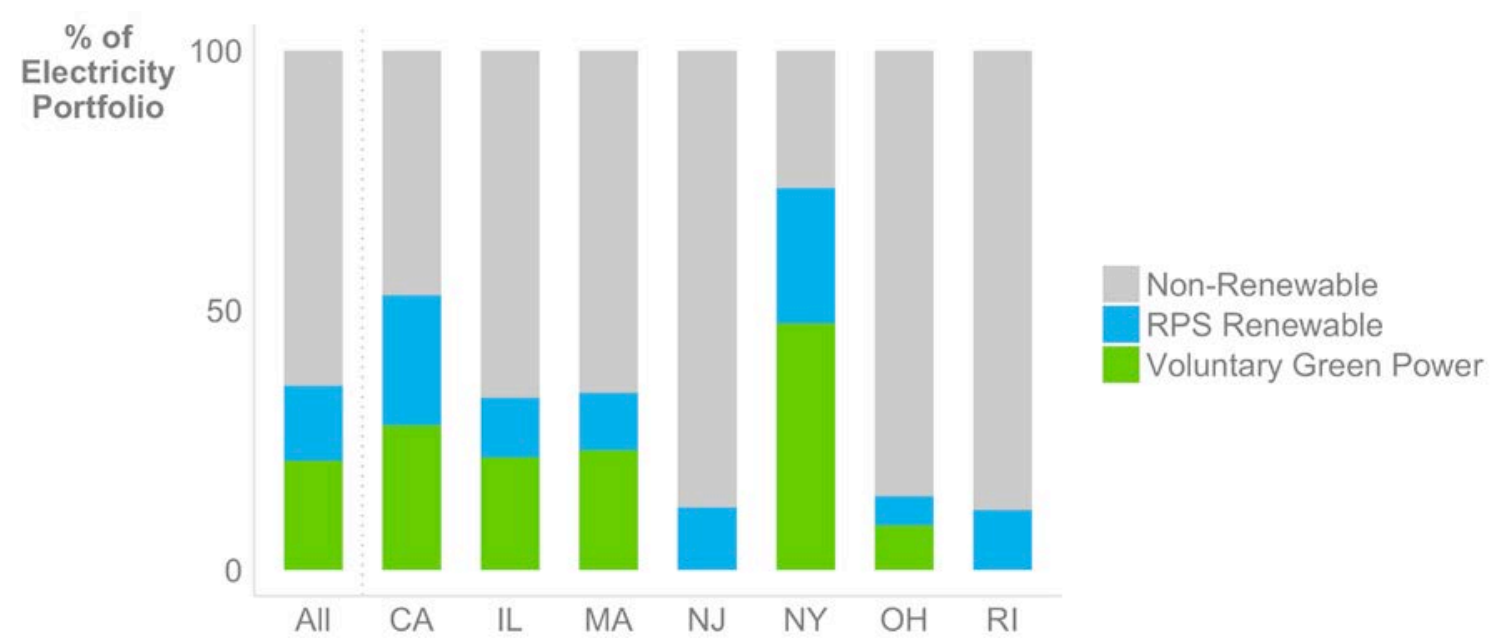

Figure ES-2. Voluntary green power shares of CCA electricity portfolios by state

CCAs accounted for about $9 \%$ of nationwide voluntary green power sales in 2016, but sales could increase if additional states enable CCAs. In addition to the eight states that already allow CCAs, at least seven other states have considered allowing CCAs (Colorado, Connecticut, New Hampshire, New Mexico, Nevada, Oregon, Utah), and other states with restructured electricity markets could pass enabling legislation. Based on current electricity use data and historic trends in CCA renewable energy procurement, we estimate that voluntary green power demand from CCAs could be as high as 62 million MWh if four of these states (CT, NH, NV, OR) and all restructured states were to enable CCAs. This could extend voluntary green power access via the CCA option to as many as 18 million customers.

However, CCAs may pose challenges to electric grids and electricity markets, and they also face challenges that could stymie their expansion. Through a literature review and interviews with 12 CCAs and other stakeholders, we identify at least 6 key challenges facing CCA expansion in general, as well as 3 challenges facing CCA expansion in regulated markets in particular: 
- Maintaining cost savings: CCAs must find ways to offer competitive rates to their customers, otherwise customers may opt out in search of lower electricity prices. To date, most CCAs have met this challenge by offering rates lower than utility rates.

- Balancing local autonomy and regional cooperation: Communities face tradeoffs between aggregating customers within a single jurisdiction (e.g., town level) versus aggregating across multiple jurisdictions (e.g., county level). Aggregating a single jurisdiction ensure high levels of autonomy over electricity supply and rates, while aggregating across jurisdictions can yield economies of scale and allow CCAs to offer more services. CCAs have used contractual structures such as joint powers agreements to aggregate across multiple jurisdictions, particularly in California. Some state- and national-level organizations have emerged to facilitate cooperation among CCAs.

- Local renewable energy procurement: All CCA interviewees expressed interest in increased procurement of local renewable energy. For CCAs in restructured electricity markets, inability to sign long-term contracts poses a challenge to local renewable energy procurement. However CCAs in restructured markets are exploring and implementing innovative ways to procure local renewables, such as through community solar and trust funds for local projects. In regulated electricity markets, CCAs are increasingly signing long-term contracts for local renewable energy, especially as CCAs mature and improve financial standing with creditors.

- Customer awareness: CCA is a new and relatively unknown concept. Interviewees reported that most CCA customers are unaware that any change has occurred in their electricity service. Interviewees reported that many CCAs and CCA organizations have implemented informational campaigns to increase customer awareness about CCAs and, in some cases, about CCA renewable energy procurement in particular.

- Customer enrollment: State-level policies determine how CCAs enroll customers that move into a CCA's service territory after CCA implementation. In certain states, movein customers automatically enrolled into utility basic service rather than into the CCA. In these states, CCAs have addressed this issue by enrolling move-in customers through periodic "sweeps," though these sweeps may increase program costs.

- Policies for CCA suspension or dissolution: Some communities have suspended or dissolved CCAs. The ability of communities to suspend CCAs may be beneficial in some cases, allowing communities to respond to changing market conditions in ways that benefit the community's residents. At the same time, CCA suspension or dissolution may undermine project developer and investor confidence in CCA investments.

- Regulated market challenges: California is the only regulated electricity market state with active CCAs. CCAs face challenges in California that are largely unique among the CCA states. California CCAs are required to pay fees designed to compensate utilities for sunk investments in long-term contracts signed on behalf of CCA customers, commonly known as exit fees. California CCAs are also subject to resource adequacy requirements that obligate CCAs to enter into long-term contracts. These and other issues are areas of ongoing discussion in California.

Our study and analysis provide early insights into the potential market impacts of the expansion of CCAs. However, numerous unanswered questions remain for future research. Will other states enable CCAs and, if so, will communities adopt CCAs at a similar scale as has been observed in states such as California, Illinois, and Massachusetts? Will CCA demand for voluntary green power-which has primarily been met by procuring renewable energy from existing 
generators - enable development of new renewable energy supply? How might CCAs compare with utilities and other load-serving entities in terms of shaping renewable energy deployment? These questions and the challenges created by CCAs are not insoluble, but they will require collaboration across a diverse set of stakeholders, including CCAs, utilities, public utility commissions, policymakers, customer advocates, and environmental groups. Our analysis is a first attempt to inform the discussion on the responsible and effective integration of CCAs into electricity and voluntary green power markets. 


\section{Table of Contents}

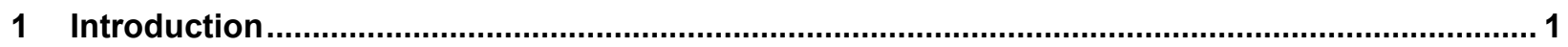

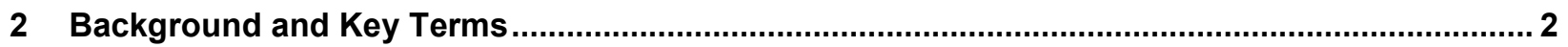

2.1 CCAs in Restructured and Regulated Electricity Markets .................................................... 2

2.2 Similarities and Differences with Other Load-Serving Entities ................................................. 3

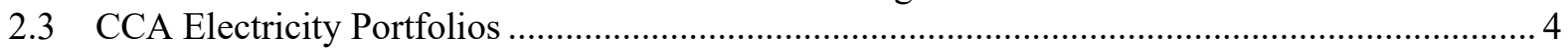

3 CCA Sales, Customers, and Voluntary Green Power ….......................................................... 7

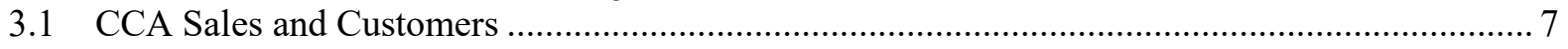

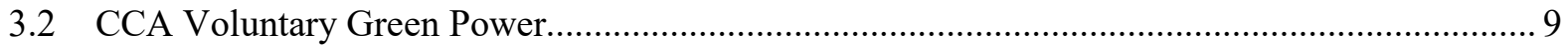

4 The Impact of CCAs on Voluntary Green Power Markets ........................................................ 12

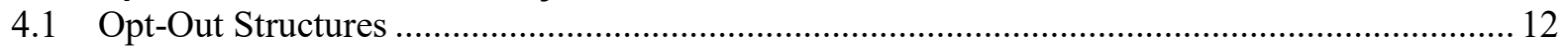

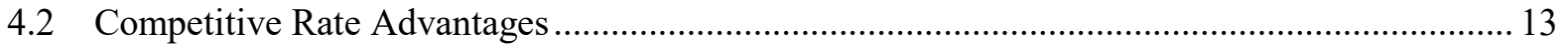

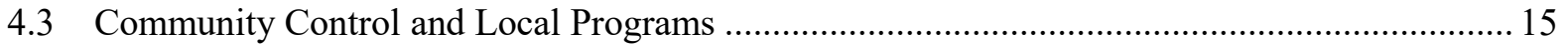

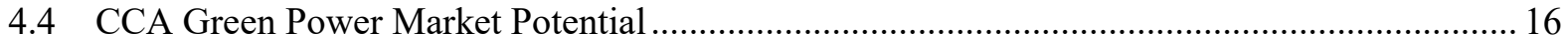

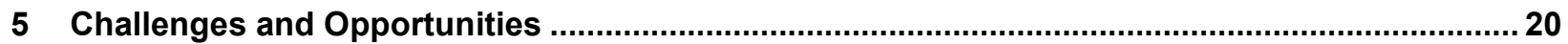

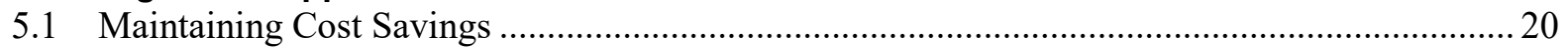

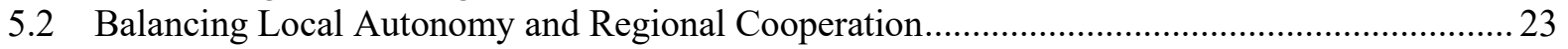

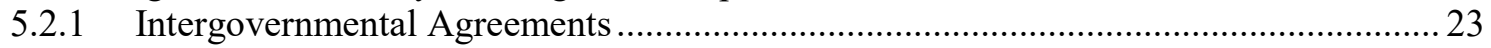

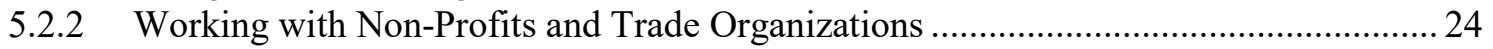

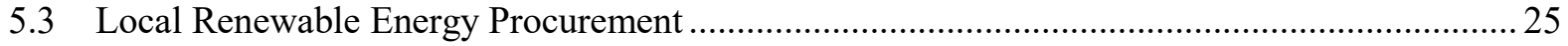

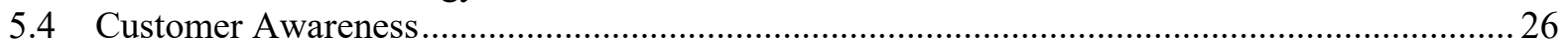

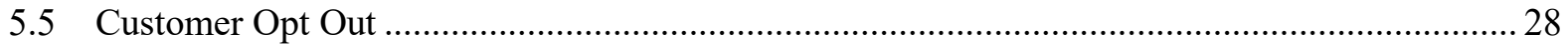

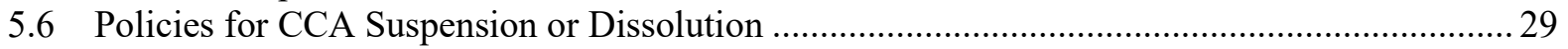

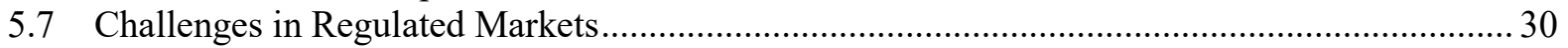

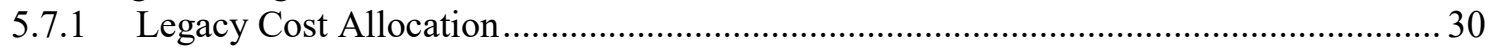

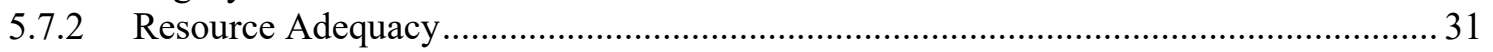

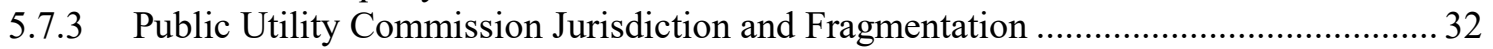

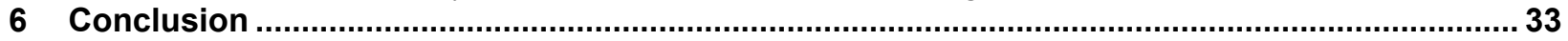

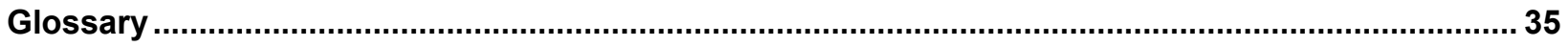

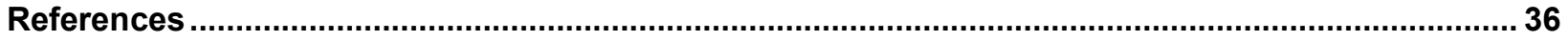

Appendix. Summary of State CCA Policies, Data, and Key Trends ........................................... 39 


\section{List of Figures}

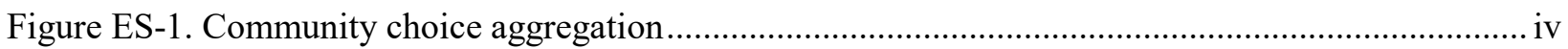

Figure ES-2. Voluntary green power shares of CCA electricity portfolios by state .................................. v

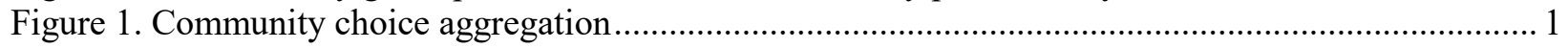

Figure 2. General CCA structures in restructured and regulated electricity markets................................. 2

Figure 3. Estimated CCA market shares by state in 2017, in terms of number of customers and sales

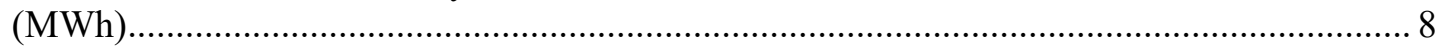

Figure 4. CCA voluntary green power shares of total electricity portfolios by state.............................. 9

Figure 5. CCA voluntary green power sales (million MWh), 2010-2017 ............................................ 10

Figure 6. CCA voluntary green power portfolios by state ................................................................ 10

Figure 7. Geographic sources of voluntary green power supply, by CCA state ...................................... 11

Figure 8. CCA rates compared to basic service rate in ComEd service territory, Illinois ......................... 14

Figure 9. States most likely to soon have CCA-enabling legislation..................................................... 17

Figure 10. Estimated voluntary green power sales and participation under three scenarios...................... 19

Figure 11. Illinois CCA sales and basic service rates, 2010-2017 .................................................... 21

Figure 12. Number of enrolled customers in Cincinnati CCA before and after a customer sweep ........... 29

\section{List of Tables}

Table 1. CCA Similarities and Differences by Electricity Market Structure............................................ 3

Table 2. Responsibilities of Load-Serving Entities............................................................................... 4

Table 3. CCA Voluntary Green Power Product Structures................................................................... 5

Table 4. Estimated CCA Statistics by State (as of December 31, 2017) ............................................... 7

Table 5. CCA-Eligible Load (Load Currently Served by Investor-Owned Utility or CCA), Based

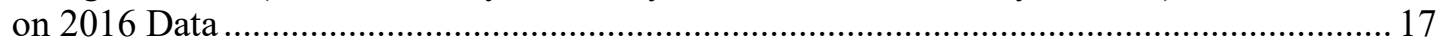

Table 6. CCA Green Power Demand Projection Assumptions.................................................................. 18 


\section{Introduction}

Community choice aggregations (CCAs) ${ }^{1}$ are local governmental entities that procure electricity on behalf of retail electricity customers within some geographic area (Figure 1). CCAs may be run directly by a city or county government or by a third party through a contractual arrangement such as a joint powers agreement. CCAs are responsible for procuring wholesale electricity on behalf of retail electricity customers while investor-owned utilities remain responsible for local transmission and distribution networks. Residents of the CCA's service area are automatically enrolled into the CCA and must deliberately opt out of the program and return to utility service if choosing not to participate. The opt-out structure requires state-level legislation that allows local governmental entities, other than utilities, to be default electricity providers. To date, eight states have passed CCA-enabling legislation: California, Illinois, Massachusetts, New Jersey, New York, Ohio, Rhode Island, and Virginia.

\section{COMMUNITY}

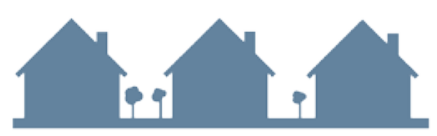

CCAs serve retail electricity customers within a given city, county, or group of jurisdictions.

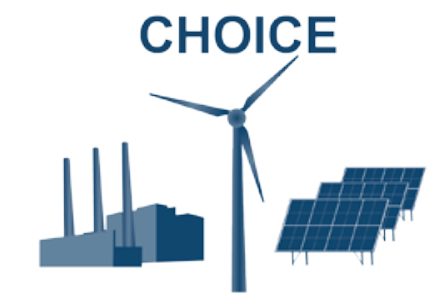

CCAs choose their own electricity portfolio, which may include renewable energy in excess of state RPS.
AGGREGATION

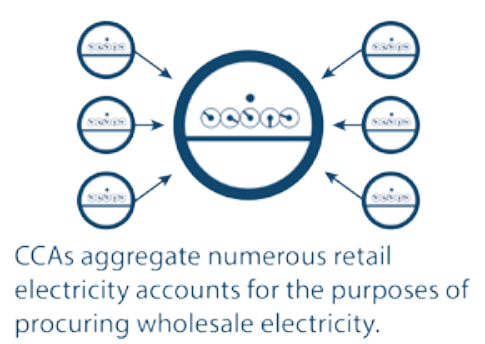

Figure 1. Community choice aggregation

The "choice" component of the term CCA reflects a key feature of aggregation: CCAs can choose the mix of resources used to supply their community's electricity, also known as an electricity portfolio (e.g., natural gas, coal, nuclear, renewable energy). In this report, we focus on how CCAs may be able to increase the amount of renewable energy in their electricity portfolios, and how CCA-driven demand for renewable energy could affect grid-wide electricity portfolios. However, CCAs could affect electricity portfolios in other ways, such as increased demand for low-cost natural gas. These additional impacts are outside the scope of this study by are an area for future research.

In this report, we seek to summarize the status of CCAs in the United States. We describe how CCAs fit into the broader context of electricity markets and load-serving entities (Section 2). We quantify CCA sales and customer bases in terms of both renewable and non-renewable energy by aggregating publicly-available data and CCA survey data (Section 3). Based on 12 interviews with CCAs and other stakeholders, we identify key factors that could determine the impacts of CCAs on renewable energy markets (Section 4). Lastly, based on the interviews and findings from the CCA literature, we identify the challenges created and faced by the expansion of CCAs (Section 5).

\footnotetext{
${ }^{1}$ CCAs have different names in different states, such as municipal energy aggregations and community choice energy. To avoid confusion, the term CCA is used throughout this report.
} 


\section{Background and Key Terms}

A CCA is formed when a local governmental body convenes and votes to aggregate its retail electricity base or when a public referendum is passed. CCAs are then generally required to issue notices to residents that the local electricity service is being switched to the CCA. CCAs may be administered either directly by the jurisdiction or by a separate entity through a contractual arrangement such as a joint powers agreement (see Section 5.2.1). A key feature of CCAs is that customers must actively opt out of the program, meaning that if a customer takes no action after receiving the notices, she is automatically enrolled into the CCA. The CCA is then responsible for procuring electricity on behalf of its residential, commercial, and municipal residents while the local utility remains responsible for transmission and distribution.

\subsection{CCAs in Restructured and Regulated Electricity Markets}

How CCAs structure themselves and procure electricity is largely influenced by whether the state electricity market is regulated or restructured, (Figure 2) as well as by state and local policy goals. The terms regulated and restructured are commonly used to describe markets where utilities provide all electricity generation services (regulated markets) and markets where nonutility entities can compete with utilities to provide electricity generation services (restructured markets). Our discussion of electricity markets requires some technical terms; see the glossary for definitions of these terms.
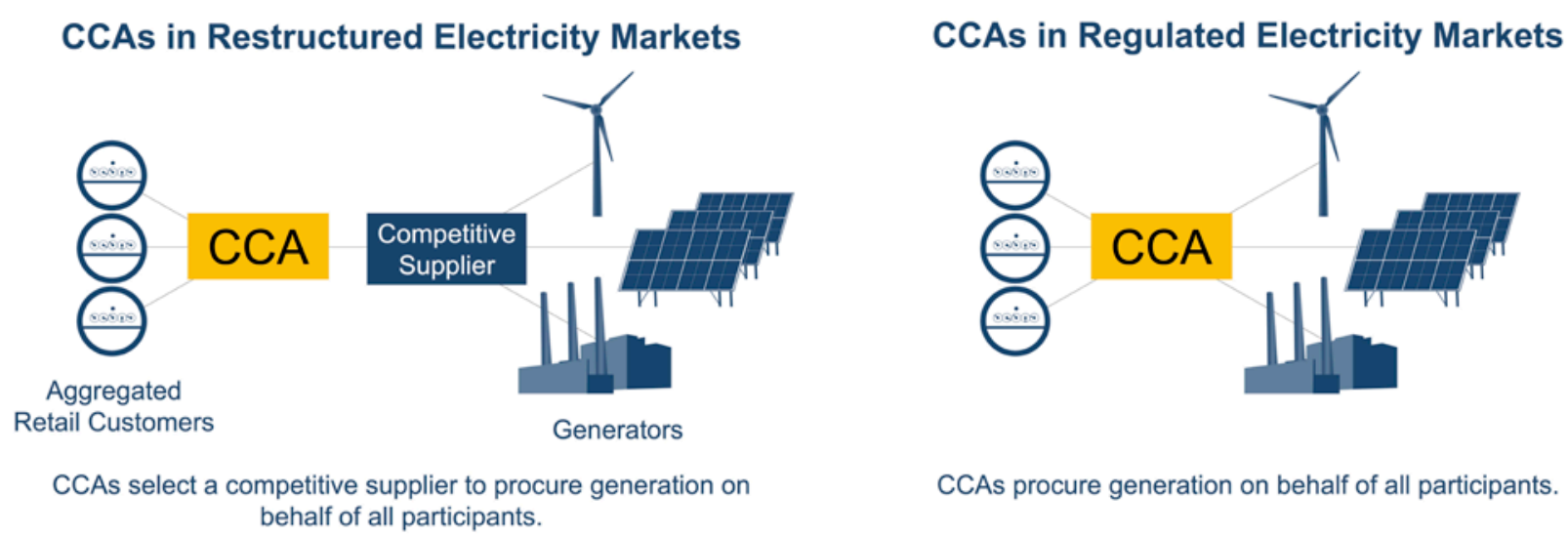

CCAs procure generation on behalf of all participants.

Figure 2. General CCA structures in restructured and regulated electricity markets

Six of the eight states that currently allow CCAs have restructured electricity markets, with California and Virginia being the exceptions with regulated electricity markets. In restructured markets, retail electricity customers can choose to procure electricity from the local distribution utility or a licensed entity known as a competitive supplier. For the purposes of this report, basic service refers to the generation provided by the local utility. Customers who do not select a competitive supplier are enrolled in basic service by default. In restructured markets, CCAs choose a competitive supplier on behalf of customers on basic service. The CCA enters into a short-term (e.g., 1-3 years) contract with a supplier to procure electricity for the CCA's customers over the contract term. CCAs generally select competitive suppliers through periodic competitive requests for proposals (RFP). 
In regulated electricity markets like California, retail electricity customers do not have the option to procure electricity from competitive suppliers and must procure it from the local regulated utility. In other words, all retail customers in regulated markets are on basic service. ${ }^{2}$ In these markets, CCAs effectively supplant the local utility to procure and sell energy to retail customers, while the utility remains responsible for consolidated customer billing, transmission and distribution, and grid maintenance. CCAs in regulated markets may be subject to various utility regulations that do not apply to CCAs in restructured markets. For instance, CCAs in regulated markets may be required to enter into long-term contracts (e.g., a minimum of 10 years) with electricity generators in order to ensure system reliability and to comply with clean power mandates.

Table 1 summarizes similarities and differences across the two market structures. In both cases, CCAs are only responsible for procurement of the generation portion of retail customer electricity service, while utilities remain responsible for transmission, distribution, and billing. The key difference is in terms of how CCAs procure that generation. In restructured markets, CCAs act like retail electricity customers; CCAs choose a competitive supplier and enter into a short-term (e.g., 1-3 years) contract for electricity service. Similar to customers in restructured markets, CCAs can switch suppliers between contract periods without penalty, or they may choose to dissolve the CCA and return customers to basic service depending on trends in electricity rates. In regulated markets, CCAs act more like utilities; they are responsible for system reliability and can contract directly with electricity generators. As we shall discuss throughout this report, both models entail unique opportunities and challenges

Table 1. CCA Similarities and Differences by Electricity Market Structure

\begin{tabular}{|c|c|c|}
\hline & Restructured Markets & Regulated Markets \\
\hline $\begin{array}{l}\text { CCA procurement } \\
\text { responsibilities }\end{array}$ & Generation & Generation \\
\hline Utility responsibilities & Transmission and distribution & Transmission and distribution \\
\hline $\begin{array}{l}\text { CCA power } \\
\text { procurement }\end{array}$ & $\begin{array}{l}\text { Short-term contracts with } \\
\text { competitive suppliers }\end{array}$ & $\begin{array}{l}\text { Short- and long-term contracts with } \\
\text { generators and electricity service providers }\end{array}$ \\
\hline
\end{tabular}

\subsection{Similarities and Differences with Other Load-Serving Entities}

CCAs are load-serving entities, meaning that they are responsible for procuring electricity generation on behalf of retail electricity customers. Other load-serving entities include municipal utilities, investor-owned utilities, competitive suppliers, and solar service providers. Table 2 defines the responsibilities of these electricity providers to clarify how CCAs differ from other load-serving entities. CCAs are unique among load-serving entities in that they are default providers of electricity generation but not responsible for transmission and distribution. CCAs are similar to municipal utilities, which are also local governmental entities that serve as the default providers of electricity. The key difference between CCAs and municipal utilities is that municipal utilities are responsible for transmission and distribution, whereas CCAs partner with

\footnotetext{
${ }^{2}$ Some states have exceptions for certain customer classes, however these exceptions do not apply to the residential and small commercial customers that generally compose CCA programs. For instance, some large commercial customers in California are allowed "direct access" to wholesale electricity supply.
} 
investor-owned utilities to provide transmission and distribution services to their customers. Investor-owned utilities are for-profit entities that act as default providers of generation, transmission, and distribution, except in CCA service areas where generation is relinquished to the CCA. CCAs are similar to competitive suppliers in that competitive suppliers only procure and sell generation, except that competitive suppliers are not default providers of retail electricity. Solar service providers are companies that sell third-party owned solar photovoltaic (PV) output to retail electricity customers. These include community solar providers where shares of a "shared" solar array are sold to multiple customers. Unlike CCAs, solar service providers are not default providers of electricity.

Table 2. Responsibilities of Load-Serving Entities

\begin{tabular}{lccc}
\hline Load-Serving Entity & Default Provider & Generation & $\begin{array}{c}\text { Transmission \& } \\
\text { Distribution }\end{array}$ \\
\hline CCA & YES & YES & NO \\
Municipal utility & YES & YES & YES \\
Investor-owned utility & YES & YES & YES \\
Competitive supplier & NO & YES & NO \\
Solar service provider & NO & YES & NO \\
\hline
\end{tabular}

\subsection{CCA Electricity Portfolios}

Like other load-serving entities, CCAs determine the mix of resources used to supply electricity to their customers, which we will refer to as an electricity portfolio (e.g., natural gas, coal, nuclear, renewable energy). In some cases, CCA electricity portfolios may not vary substantively from the portfolios of other load-serving entities. However, as we demonstrate in Section 3, the expansion of CCAs could affect grid-wide electricity portfolios if CCAs exhibit preferences for specific resources, such as renewable energy or low-cost natural gas.

All CCAs are required to comply with state renewable portfolio standards (RPS) requirements. An RPS is a policy mandating that load-serving entities procure a specified amount of their electricity portfolios from renewable energy generators. Throughout this report, the term RPScompliant power refers to an electricity portfolio that meets but does not exceed state RPS requirements. Some CCAs choose to procure renewable energy beyond the amount specified by the state's RPS. Indeed, some communities may choose to form CCAs explicitly in order to increase the renewable energy content of their community's electricity portfolio. The term voluntary green power refers to the portion of an electricity portfolio that exceeds the state RPS. In general, utility basic service offers RPS-compliant power, though basic service in some service areas may exceed the RPS. Throughout this report, the term voluntary green power always refers to the incremental portion of renewable energy above the RPS procured by a CCA. For instance, if a CCA offers a $100 \%$ renewable energy product in a state with a $10 \%$ RPS, our estimate of voluntary green power sales is equal to $90 \%$ of the CCA's total sales.

Some state RPS require that load-serving entities procure renewable energy with specific characteristics. For instance, an RPS may require that the renewable energy be generated within 
the state or within the region or that a specific percentage of the renewable energy come from a specific resource such as solar. We do not extend these requirements to our definition of voluntary green power. In other words, if a CCA offers 100\% renewable energy, the voluntary green power portion of that renewable energy is not necessarily RPS-compliant. As a result, CCA voluntary green power portfolios are not necessarily the same as CCA RPS-compliant portfolios or utility renewable energy portfolios.

Renewable energy sales are tracked and validated by accounting mechanisms known as renewable energy certificates (RECs). One REC is equal to the clean energy attributes of one megawatt-hour of renewable electricity. RECs may be "bundled" and sold with electricity or "unbundled" and sold separately from the underlying electricity. For instance, a CCA may sign a power purchase agreement with a renewable energy generator that will deliver a specific amount of electricity and RECs from a particular renewable energy generator. In this scenario, the CCA would receive bundled RECs. Alternatively, a CCA may purchase electricity from the wholesale market or a non-renewable energy generator and buy unbundled RECs to match their electricity needs. Procuring bundled and unbundled RECs entail different benefits and challenges, as we discuss throughout the report.

CCA voluntary green power program structures can vary (Table 3). In the simplest structure, the CCA integrates voluntary green power content into its standard opt-out offering, such that all customers receive the same voluntary green power content. Some CCAs offer RPS-compliant service but allow their customers to opt in to a voluntary green power product. Some CCAs offer an "opt-up" voluntary green power product in addition to an opt-out voluntary green power product. For instance, a CCA may offer a standard 50\% renewable energy portfolio by default (opt out) and offer their customers the option to opt up to a $100 \%$ renewable energy portfolio for an extra cost. A third approach would be to enroll customers in voluntary green power by default (opt out) but allow customers to opt down to a lower-cost RPS-compliant power product. This opt-down structure may allow CCAs to offer voluntary green power but still retain customers that are unwilling or unable to pay for a voluntary green power premium.

Table 3. CCA Voluntary Green Power Product Structures

\begin{tabular}{ll}
\hline Structure & Description \\
\hline Opt out & All customers receive voluntary green power by default. \\
Opt in & $\begin{array}{l}\text { Customers can choose to switch from RPS-compliant to voluntary green power at an } \\
\text { extra cost. }\end{array}$ \\
Opt up & $\begin{array}{l}\text { Customers can choose to switch from a voluntary green power product to a product with } \\
\text { higher renewable energy content or a specific type of renewable (e.g., local solar). }\end{array}$ \\
Opt down & $\begin{array}{l}\text { All customers receive voluntary green power by default, but customers can choose to } \\
\text { opt down to a lower-cost RPS-compliant product. }\end{array}$ \\
\hline
\end{tabular}


Finally, throughout this report, we summarize CCA efforts to procure local renewable energy. However, there is no single criterion on which to judge whether a resource is local. For instance, CCAs in Massachusetts tend to cover relatively small geographic areas, often only encompassing a single town. For such CCAs, a "local" product may refer to generation from within the state or from nearby northeastern states. In contrast, California CCAs often cover large enough geographic areas that a "local" product may refer to a generator within the CCA's service area. We use the term local throughout this report to refer to in-state or regional resources, even though such resources may not satisfy the locality criteria of specific CCAs. 


\section{CCA Sales, Customers, and Voluntary Green Power}

In this section, we summarize the key trends in sales and participation in the seven states that have active CCAs, ${ }^{3}$ in terms of all power (Section 3.1) and voluntary green power specifically (Section 3.2).

\subsection{CCA Sales and Customers}

We estimate that in 2017 about 750 CCAs procured 42 million MWh of electricity on behalf of five million customers (Table 4 ). These figures equate to about $5 \%$ of retail sales and $12 \%$ of retail customers in the seven CCA states. At the national level, about $4 \%$ of U.S. retail electricity customers were served by a CCA in 2017 , though CCA sales only represent about $1 \%$ of all retail electricity sales. ${ }^{4}$ The discrepancy between participation and sales stems from the focus of CCAs on residential and small commercial customers with relatively small loads. CCA sales could increase significantly in the near future, with a projected increase of 10 million MWh in sales in California alone (CalCCA 2018a).

Table 4. Estimated CCA Statistics by State (as of December 31, 2017)

\begin{tabular}{lrrrrr}
\hline & $\begin{array}{l}\text { Number } \\
\text { of CCAs }\end{array}$ & $\begin{array}{l}\text { Sales } \\
\text { (million } \\
\text { MWh/year) }\end{array}$ & $\begin{array}{l}\text { Number of } \\
\text { Customers } \\
(\mathbf{x 1 , 0 0 0 )}\end{array}$ & $\begin{array}{l}\text { Percentage } \\
\text { of Total } \\
\text { State Sales }\end{array}$ & $\begin{array}{l}\text { Percentage } \\
\text { of Total State } \\
\text { Customers }\end{array}$ \\
\hline California & 9 & 11.8 & 1,239 & $5 \%$ & $8 \%$ \\
Illinois & 490 & 16.2 & 1,960 & $11 \%$ & $34 \%$ \\
Massachusetts & 110 & 5.1 & 870 & $10 \%$ & $27 \%$ \\
New Jersey & 15 & 1.7 & 210 & $2 \%$ & $5 \%$ \\
New York & 1 & 0.7 & 93 & $0.4 \%$ & $1 \%$ \\
Ohio & 120 & 6.6 & 660 & $4 \%$ & $12 \%$ \\
Rhode Island & 1 & 0.2 & 2 & $3 \%$ & $0.4 \%$ \\
\hline Total & $\mathbf{7 5 0}$ & $\mathbf{4 2}$ & $\mathbf{5 , 0 0 0}$ & $\mathbf{5 \%}$ & $\mathbf{1 2 \%}$ \\
\hline
\end{tabular}

See the appendix for data sources, total state sales and customers, based on EIA (2018a).

CCAs have achieved the most market penetration in Illinois, which is followed closely by Massachusetts and California (Figure 3). In every state except Rhode Island, CCAs have achieved greater market penetration in terms of customers than in terms of megawatt-hours because CCAs primarily serve residential and small commercial customers. In Rhode Island, CCAs only serve governmental customers (e.g., municipal buildings) with relatively higher electricity demands per customer. New York - the most recent state to enable CCA - is poised to become the next major CCA market: at least 50 communities in New York have passed local laws to form CCAs (Binns 2018).

\footnotetext{
${ }^{3}$ CCAs are enabled in Virginia, but there is no current CCA activity there.

${ }^{4}$ This figure is based on 2017 retail electricity usage and customer account data from the U.S. Energy Information Administration (EIA).
} 


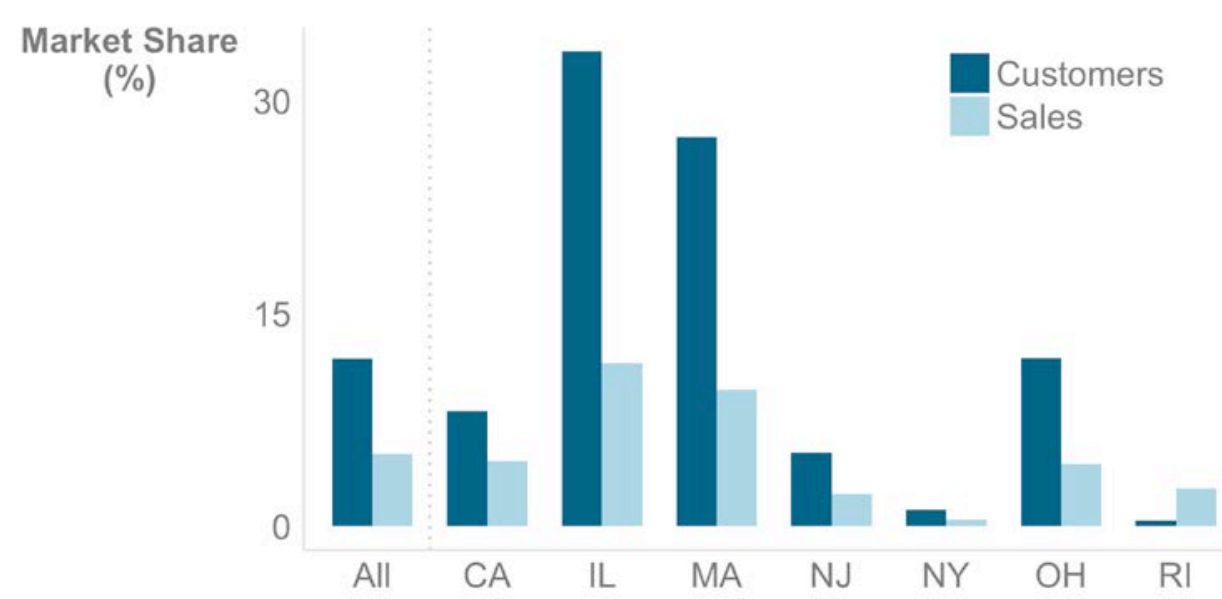

Figure 3. Estimated CCA market shares by state in 2017, in terms of number of customers and sales (MWh)

See the appendix for data sources.

On average, an individual CCA procures about 61,000 MWh per year on behalf of about 7,600 customers. However, this national-level average masks broad variation in CCA program size. Just 9 CCAs in California accounted for about 12 million MWh of sales in 2017, or about 1.3 million MWh per CCA. Similarly, a single CCA in New York sold about 0.7 million MWh in 2017. In contrast, CCAs in the remaining states are generally far smaller, operating on the order of thousands rather than millions of megawatt-hours per year. These disparities stem from differences in CCA program structures. Communities may choose to implement a CCA in isolation at the level of a town or city. Alternatively, communities may cooperate to implement a CCA at the level of a county or region. Most CCAs in states like Illinois, Massachusetts, and Ohio have implemented the town- or city-level model, while CCAs in California have implemented the cooperative model, resulting in CCAs that serve entire counties or span multiple counties. We discuss the benefits and challenges of intercommunity cooperation in CCAs in Section 5.2.

According to survey data and interviews with CCAs, about 5\%-15\% of eligible customers opt out of CCAs, on average. ${ }^{5}$ In other words, $85 \%-95 \%$ of CCA-eligible customers tend to remain with the CCA rather than revert to basic service. Low customer opt-out rates suggest that CCAs have been able to offer competitive rates with basic service in order to maintain high customer retention (see Section 4.2). As we discuss in Section 5.4, most CCA customers may be generally unaware of changes in their electricity supply and will not act to actively switch supply as long as rates are low. Alternatively, low customer opt outs may reflect some degree of self-selection: CCAs may tend to form in areas where communities feel that cost savings could be achieved over basic service, and CCAs may discontinue service when CCA rates are no longer competitive. For instance, more than 200 CCAs in Illinois discontinued service following a period of falling basic service rates (ICC 2018a). See Section 5.1 for a discussion of the challenges of CCA cost-competitiveness.

\footnotetext{
${ }^{5}$ The motivations behind customer opt outs are unclear, particularly when CCA rates are lower than basic service rates. Anecdotally, interviewees reported that some customers opt out on principle for being opposed to any program that automatically changes customer electricity service.
} 


\subsection{CCA Voluntary Green Power}

In 2017, about 100 of the 750 active CCAs offered a voluntary green power product. ${ }^{6} \mathrm{We}$ estimate these CCAs procured about 8.9 million MWh of voluntary green power on behalf of 2.7 million customers. The voluntary green power share of total CCA sales varies geographically (Figure 4). Voluntary green power currently accounts for the greatest share of CCA electricity sales in New York, where a single CCA offers opt-out and opt-in voluntary green power products. Voluntary green power sales in Illinois and Massachusetts are led by numerous communities that offer opt-out voluntary green power products, often at $100 \%$ renewable energy. Voluntary green power CCA sales in Ohio are driven by $100 \%$ opt-out voluntary green power programs, though other CCAs offer opt-in voluntary green power. In California, most CCAs offer electricity portfolios that exceed the state RPS. ${ }^{7}$ However, because most California CCAs do not offer opt-out $100 \%$ renewable energy products and because the California state RPS is relatively high, voluntary green power sales in California compose a small share of overall CCA sales. No CCAs in New Jersey or Rhode Island currently offer voluntary green power products.

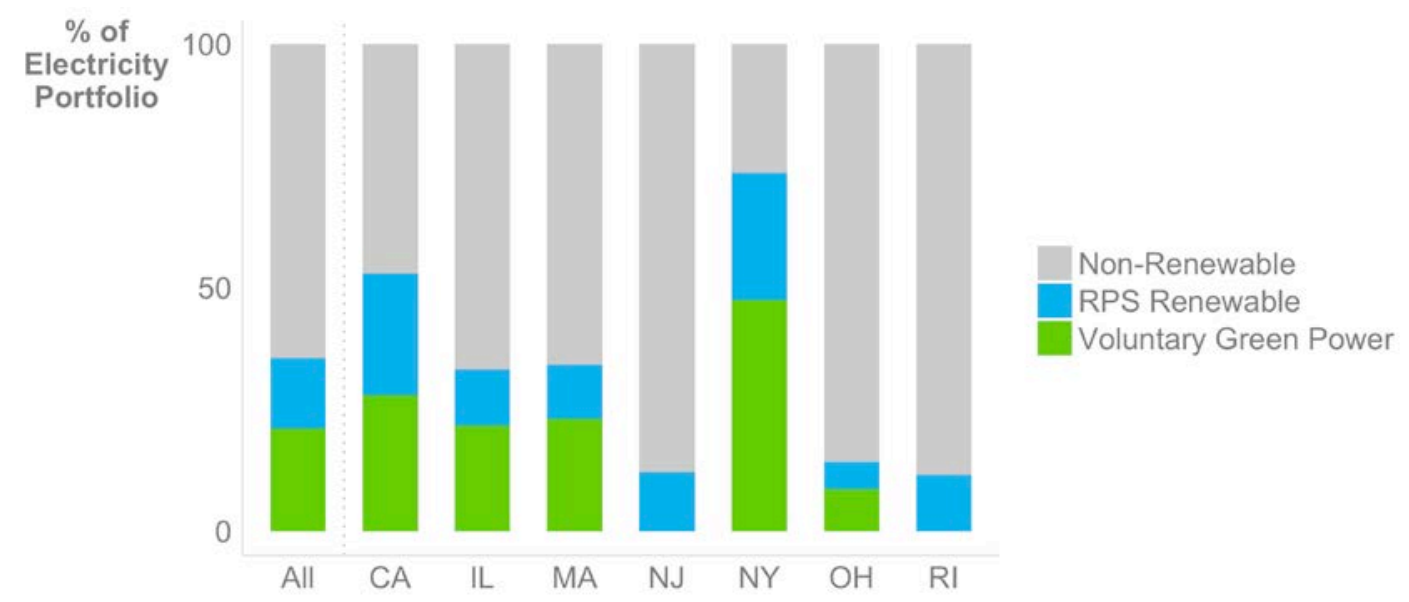

Figure 4. CCA voluntary green power shares of total electricity portfolios by state

Voluntary green power sales through CCAs fell from 2013 to 2015 before increasing from 2015 to 2017 (Figure 5). The initial decline was driven by falling voluntary green power sales in Illinois (see Section 5.1 for an explanation of this trend). The recent increase in voluntary green power sales is driven by increasing sales in California and Massachusetts, as well as the implementation of the first CCA in New York. In California, growth in voluntary green power sales is driven largely by the rapidly increasing number of programs, all of which offer voluntary green power products by default. In Massachusetts, growth in voluntary green power is similarly driven by an increasing number of programs, but also by the decision of a single large CCA to switch from a voluntary opt-in green power product to a default opt-out voluntary green power product in 2017 (see Section 4.1). That switch alone increased voluntary green power sales in Massachusetts by about 875,000 MWh from 2016 to 2017.

\footnotetext{
${ }^{6}$ These figures refer to the number of CCAs that offer voluntary green power by default. Additional CCAs offer optional opt-in voluntary green power products, however participation in these products is generally very low, typically with less than $1 \%$ of eligible customers choosing to opt in.

${ }^{7}$ It should be noted that the electricity portfolios of the state's investor-owned utilities, particularly San Diego Gas \& Electric, also exceed RPS.
} 


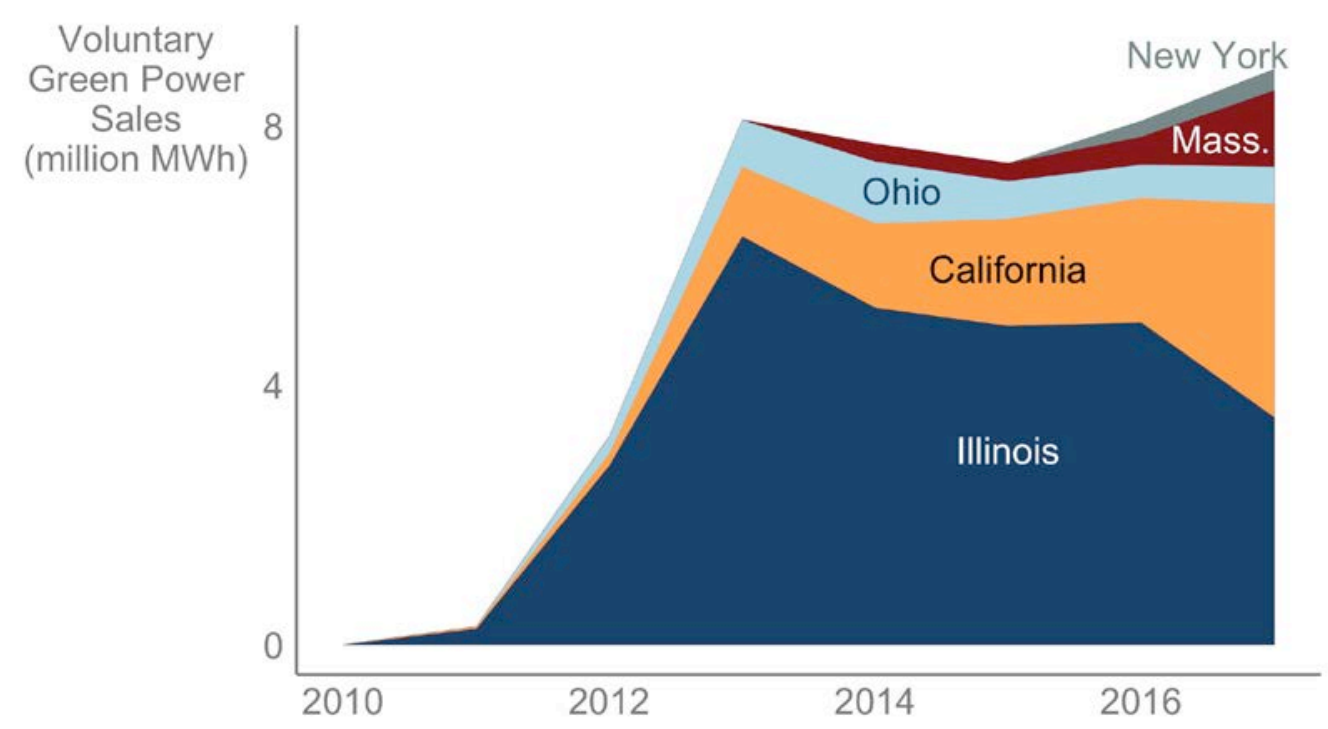

Figure 5. CCA voluntary green power sales (million MWh), 2010-2017

Wind energy accounts for about $78 \%$ of all CCA voluntary green power sales (Figure 6). The disproportionate use of wind in CCA voluntary green power portfolios is consistent with other voluntary green power products such as utility green pricing (O'Shaughnessy, Heeter, and Sauer 2018). Installed wind capacity is abundant relative to solar, and wind REC prices are generally lower than solar REC prices, though REC prices vary by region (O'Shaughnessy, Heeter, and Sauer 2018). By relying heavily on wind, CCAs may be able to reduce voluntary green power premiums and offer cost-competitive voluntary green power products. CCA voluntary green power resource portfolios are more diverse in California, where they are composed of about $52 \%$ wind, $18 \%$ solar, $12 \%$ geothermal, $9 \%$ hydro, and $8 \%$ biomass.

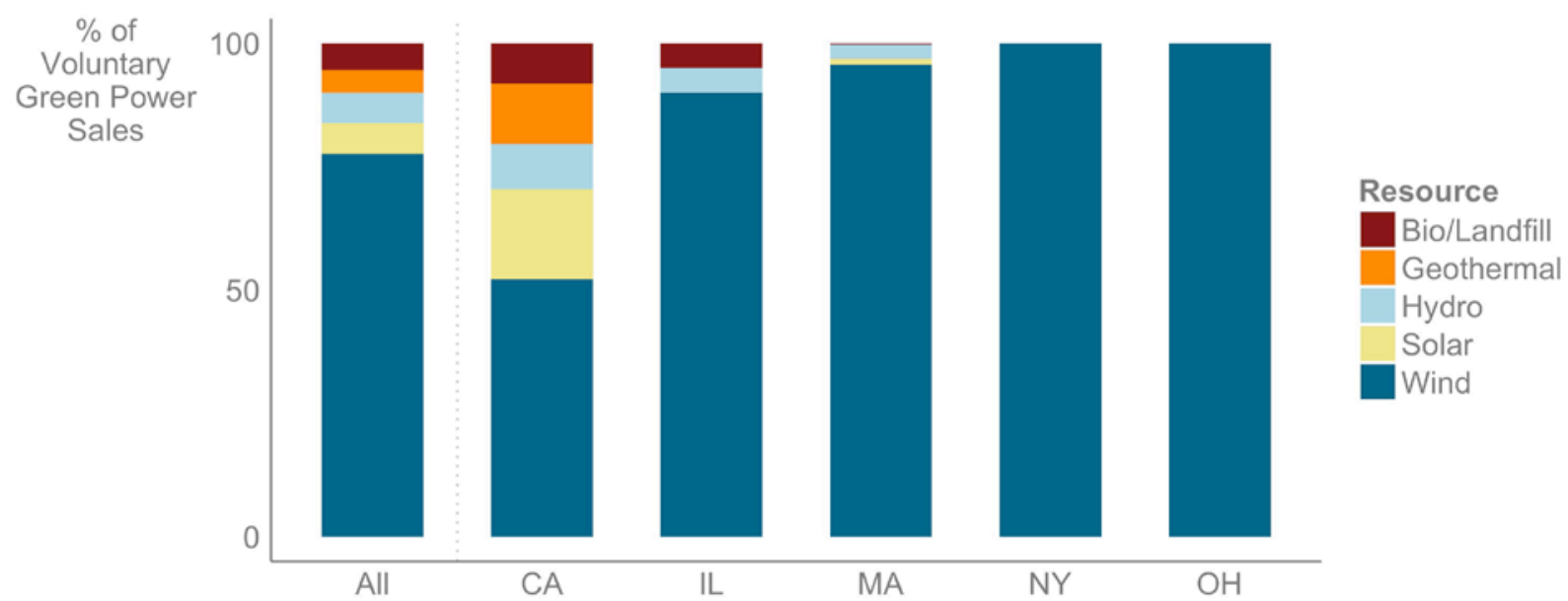

Figure 6. CCA voluntary green power portfolios by state

To analyze the geographic distribution of voluntary green power portfolios, we organize voluntary green power sales into three categories: in-state, regional, and national. Regional is defined as a resource from a state bordering the CCA's state or located within the CCA state's REC tracking 
system. ${ }^{8}$ Nationally sourced green power refers to all renewable energy sources outside the CCA's tracking system, which derives primarily from wind farms in Texas. In-state and regional renewable energy accounts for about $35 \%$ and $38 \%$ of all CCA voluntary green power respectively. California CCAs procure about half of their voluntary green power from within the state and the other half from regional generators. CCAs in Illinois have emphasized regional sourcing of wind power (Englum et al. 2014). Outside California and Illinois, most CCA voluntary green power is sourced from out-of-state resources (Figure 7). CCAs in Massachusetts, New York, and Ohio rely almost exclusively on nationally sourced wind RECs, mostly from Texas. At least nine CCAs in Massachusetts offer regional wind products, and some CCAs are exploring how to integrate in-state community solar offerings into their electricity portfolios.

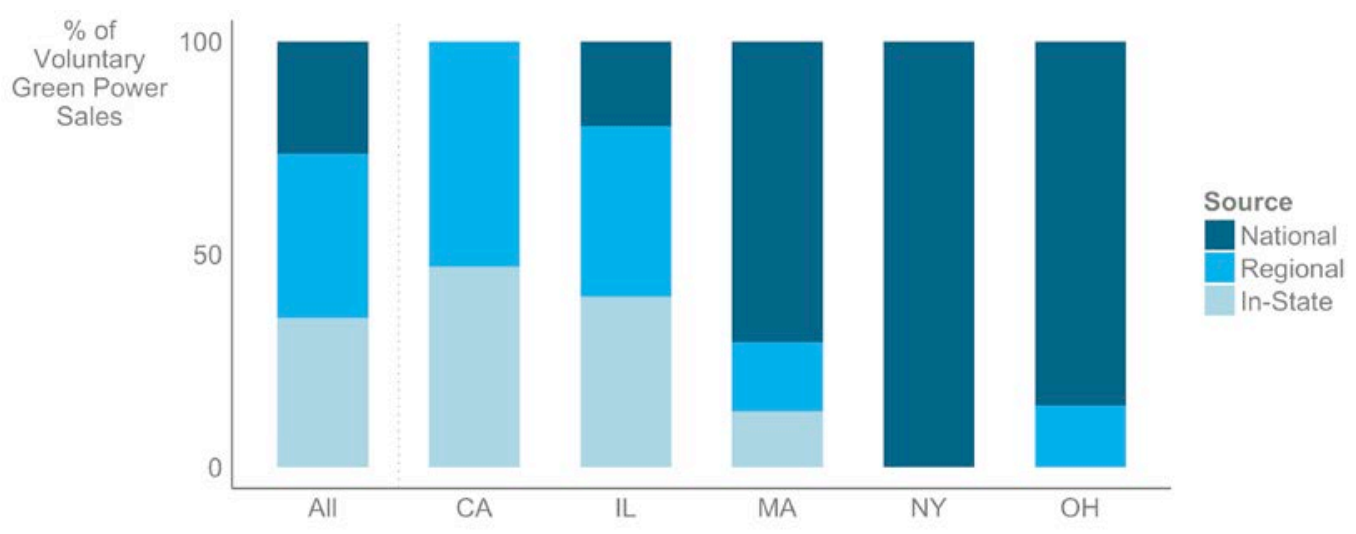

Figure 7. Geographic sources of voluntary green power supply, by CCA state

The ability of California CCAs to source more in-state and regional renewable energy stems in part from their ability to sign long-term contracts. 9 Long-term contracts provide more financial stability for renewable energy developers than do short-term contracts. Hence the ability to sign long-term projects improves the ability of CCAs to work with local renewable energy developers. While newly formed CCAs generally rely on short-term contracts, California CCAs are increasingly pivoting toward long-term (>10 years) contracts (Gattaciecca, DeShazo, and Trumbull 2018).

California's two more-established CCAs have procured about $700 \mathrm{MW}$ of new in-state solar, 300 MW of new in-state wind, and $10 \mathrm{MW}$ of new in-state biogas (CalCCA 2018a). Long-term contracts provide enough financial certainty for suppliers and developers to implement new in-state or regional renewable energy projects. In contrast, CCAs outside California procure renewable energy through shorter-term ( $<3$ years) contracts with competitive suppliers. Short-term contracts reduce CCA and customer risk, but also generally provide too little financial certainty to allow suppliers to develop new in-state renewable energy projects. We explore these issues in Section 5.3.

${ }^{8}$ For the five CCA states with voluntary green power programs, the regions are defined as follows:

- CA: AZ, CO, ID, MT, NM, NV, OR, UT, WA, WY, and British Columbia

- IL: IA, IN, KY, MN, MT, MO, ND, OH, SD, and WI

- MA: CT, ME, NH, NY, RI, and VT

- OH: DE, IN, KY, MD, NJ, PA, VA, and WV

- $\quad$ NY: CT, MA, NJ, PA, and VT.

${ }^{9}$ It should be noted that the large share of in-state and regional renewable energy in California CCA electricity portfolios also stems from the large geographic expanse of California and the western regional REC tracking system. 


\section{The Impact of CCAs on Voluntary Green Power Markets}

CCAs are one option in a suite of methods for retail electricity customers to procure voluntary green power that includes utility green pricing programs and competitive supplier voluntary green power sales (O'Shaughnessy, Heeter, and Sauer 2018). ${ }^{10}$ CCAs present an approach that is fundamentally different than these other voluntary green power products and which could both significantly increase customer access to voluntary green power and increase voluntary green power sales in the United States. In this section, we use findings from 12 interviews with CCA stakeholders and from the CCA literature to explore three key attributes of CCAs that could have significant implications for U.S. voluntary green power demand. Based on these attributes and historical trends in CCAs, we estimate the potential impacts of CCA expansion on U.S. voluntary green power demand.

\subsection{Opt-Out Structures}

All non-CCA voluntary green power products are opt-in products, meaning retail electricity customers must actively choose to switch from RPS-compliant power to voluntary green power. The opt-out structure used by CCAs is far more effective than opt-in structures in terms of voluntary green power customer acquisition and retention. The efficacy of opt out can be measured through program participation rates. According to interviews with CCAs, typical optout rates are on the order of 5\%-15\%, meaning about $85 \%-95 \%$ of eligible customers remain in CCAs. In contrast, top-performing utility green pricing programs achieve program participation rates on the order of 5\%-20\% (NREL 2018). Largely because of the opt-out structure, more customers procure voluntary green power through CCAs than through any other voluntary green power product (O'Shaughnessy, Heeter, and Sauer 2018). CCAs accounted for about half of all voluntary green power customers in 2017.

The experience of the Cape Light Compact CCA in the Cape Cod region of Massachusetts illustrates the power of the opt-out structure. Before 2017, Cape Light Compact offered customers the option to opt into a $50 \%$ or a $100 \%$ renewable energy product. In 2017, Cape Light Compact began offering 100\% renewable energy by default (opt out). With the switch from opt in to opt out, Cape Light Compact increased voluntary green power sales from about 4,700 MWh in 2016 to about 880,000 MWh in 2017.

Findings from behavioral economics help explain why opt out is more effective than opt in in terms of renewable energy sales. Empirical data show that decision makers exhibit a bias toward the default option, meaning the option that will occur if the decisionmaker takes no action (Tversky and Kahneman 1991). The default bias has been observed in electricity markets; customers tend to procure default electricity products even if alternative voluntary green power products are available and even if those customers state a preference for voluntary green power (Pichert and Katsikopoulos 2008; Frederiks, Stenner, and Hobman 2015). Put another way, customers that have expressed willingness to buy voluntary green power tend not to make the active effort to switch away from their default electricity products, even if their electricity

\footnotetext{
${ }^{10}$ In a utility green pricing program, utilities procure and retire voluntary green power on behalf of customers that choose to opt in to the program. Some competitive suppliers offer their customers the option to choose an electricity portfolio with voluntary green power.
} 
supplier offers a voluntary green power product. These customers may be unaware of their voluntary green power options or may simply be unwilling to incur the time and effort needed to switch their choice of electricity supply. Hence, by setting CCA service as the default option, default bias works to increase participation in CCAs relative to opt-in programs like utility green pricing.

\subsection{Competitive Rate Advantages}

While some CCA customers may be willing to pay a premium for voluntary green power (Farhar 1999; Aldy and Kotchen 2012; Ma et al. 2015), CCAs may be able to offer a voluntary green power product without increasing customer opt out if CCAs can offer voluntary green power at a lower price than basic service. All CCA interviewees reported offering lower rates than basic service, and publicly available data generally suggest that CCA rates are at least competitive with basic service (Gattaciecca, Trumbull, and DeShazo 2017; ICC 2018a; ICC 2018b). The bases for CCA competitive rate advantages differ in restructured and regulated markets.

In restructured markets, CCAs wield more bargaining power with competitive suppliers than do individual customers, such that CCAs may be able to negotiate lower contract prices with suppliers and offer competitive rates to their customers (The Solar Foundation 2013; Henderson 2017). To illustrate, consider the perspective of a competitive supplier bidding to an individual residential customer versus bidding to a CCA. In the case of the residential customer, the supplier stands to win or lose sales to a single customer. Furthermore, individual customers tend to be less informed about electricity markets, so that the supplier may be able to increase prices slightly without losing customers. Indeed, despite the theory that retail competition should yield lower electricity rates, empirical evidence generally shows that individual retail customers do not save, and even possibly lose, money by switching away from basic service (Defeuilley 2009; Borenstein and Bushnell 2015; Baldwin 2018). In contrast, when bidding to a CCA, the competitive supplier stands to win or lose sales to thousands or even hundreds of thousands of customers, incentivizing the supplier to offer a low competitive bid. Furthermore, the CCA may have more market expertise than individual customers, which could help them negotiate more competitive rates with suppliers.

All CCA interviewees from restructured markets reported offering retail rates that are lower than basic service, though in some cases CCA rates can exceed basic service rates during certain times of the year. As an illustrative example, about $76 \%$ of the 178 active CCAs in the ComEd service territory of Illinois currently offer a rate equal to or lower than basic service (Figure 8). ${ }^{11}$

\footnotetext{
11 This figure is based on data from ICC (2018a; 2018b). The basic service rate is based on average ComEd "rate to compare" from July 2017 to August 2018.
} 


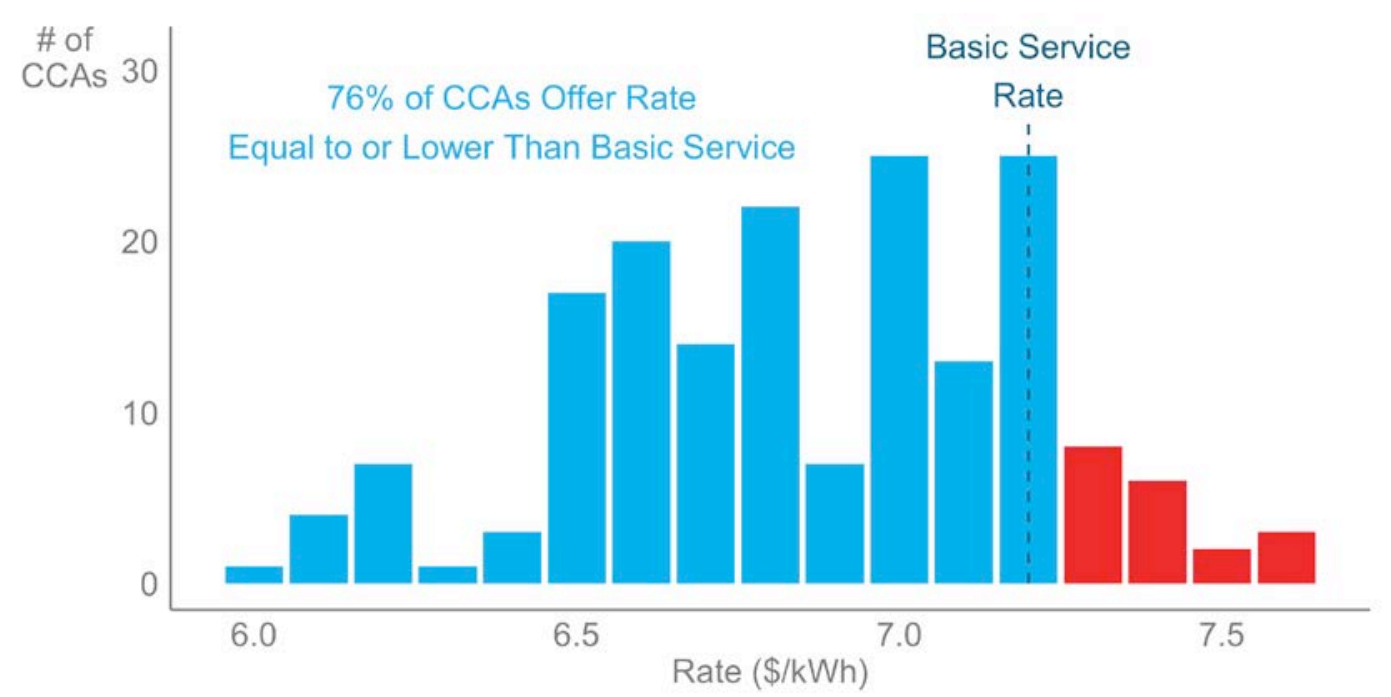

Figure 8. CCA rates compared to basic service rate in ComEd service territory, Illinois

Based on data from ICC (2018a; 2018b)

Many CCAs have used the cost advantage to offer low-cost voluntary green power. All CCA interviewees reported offering voluntary green power at a discount to basic service. ${ }^{12}$ The ability of CCAs to offer voluntary green power at a discount to or at rates competitive with basic service is a significant development. Traditional residential voluntary green power products such as utility green pricing and competitive supplier voluntary green power almost always entail premiums over basic service, generally on the order of $\$ 0.01 / \mathrm{kWh}$, though they can be as high as $\$ 0.05 / \mathrm{kWh}$ depending on the voluntary green power resource procured (O'Shaughnessy, Heeter, and Sauer 2018). ${ }^{13}$ The premiums reflect the cost of the RECs procured to back the voluntary green power product plus any administrative fees charged by the voluntary green power provider. CCAs may be able to use their competitive rate advantages to offer a blended rate with electricity plus RECs that still beats basic service rates. For instance, if a CCA negotiates a rate with a supplier that is $\$ 0.02 / \mathrm{kWh}$ less than basic service and then adds a $\$ 0.01 / \mathrm{kWh}$ voluntary green power premium, the rate is still $\$ 0.01 / \mathrm{kWh}$ less than basic service. Insofar as rate advantages allow CCAs to offer voluntary green power, the potential impacts of CCAs on voluntary green power demand may therefore depend on local electricity prices. In other words, CCAs may be able to more effectively absorb voluntary green power premiums in markets with higher basic service rates. Indeed, this may explain why many CCAs offer voluntary green power in Massachusetts - where average residential rates are $\$ 0.22 / \mathrm{kWh}$ - while only two CCAs offer voluntary green power in Ohio, where average residential rates are $\$ 0.13 / \mathrm{kWh}$. Nonetheless, other non-economic factors may explain differences in voluntary green power offerings across states and across CCAs.

CCA rate advantages are likely to be different in regulated markets such as California than in restructured markets. Specifically, at least some of the currently observed CCA rate advantages in California may reflect temporary benefits from favorable contractual rates (Gattaciecca,

\footnotetext{
${ }^{12}$ Some CCAs offer optional regional or $100 \%$ renewable energy products that entail higher rates.

${ }^{13}$ Large non-residential customers can use various voluntary green power procurement methods to obtain voluntary green power at a discount relative to RPS-compliant power. See O'Shaughnessy, Heeter, and Sauer (2018) for a discussion of other voluntary green power procurement methods.
} 
Trumbull, and DeShazo 2017). In California, new CCAs can sign long-term contracts for renewable energy at historically low prices. In contrast, over $97 \%$ of the investor-owned utility renewable energy supply is based on long-term contracts, the majority of which were signed when renewable energy prices were significantly higher (Gattaciecca, DeShazo, and Trumbull 2018). As a result, CCAs wield a temporary cost advantage over basic service until the utilities sign new renewable energy contracts. This cost advantage is at least partially offset by California regulations requiring CCA customers to continue to pay sunk utility costs through an "exit fee" (Gattaciecca, DeShazo, and Trumbull 2018). However, some utilities have argued that current exit fees are based on a "flawed" cost allocation mechanism (PG\&E and SDG\&E 2018). An exit fee that is set too low or too high grants a cost advantage to the CCA or the utility, respectively. These issues are explored in Section 5.7.1.

\subsection{Community Control and Local Programs}

Dozens of cities and counties have committed to procuring $100 \%$ renewable energy, and renewable energy goals figure prominently in city and county sustainability policies around the country. However, most jurisdictions have relatively little control over their retail electricity supply. One option is for jurisdictions to form municipal utilities. Municipalization transfers responsibilities for electricity generation as well as transmission and distribution to the local jurisdiction. CCA provides an alternative to municipalization that allows jurisdictions to control electricity supply without taking charge of local transmission and distribution. Several CCA interviewees noted that CCA offers a lower-cost and simpler alternative to municipalization that allows them to achieve many of the same goals. Major cities that have already integrated CCAs into 100\% renewable energy plans include Berkeley, Cincinnati, San Diego, and San Francisco. CCAs could play a significant role in the renewable energy strategies of jurisdictions that choose not to or cannot municipalize.

Community control of electricity supply through CCAs could also affect where and how voluntary green power is generated. Trends in voluntary green power markets suggest that green power customers prefer local renewable resources, especially local solar (O'Shaughnessy, Heeter, and Sauer 2018). By shifting voluntary green power resource selection to the community rather than the utility or supplier level, CCAs may result in increased procurement of local renewable energy. For instance, some California CCAs incentivize rooftop solar through feed-in tariffs or other structures that are more generous than utility offerings (Gattaciecca, Trumbull, and DeShazo 2017). MCE ${ }^{14}$ and Sonoma Clean Power, two California CCAs, have $3.2 \mathrm{MW}$ and $5.99 \mathrm{MW}$ of solar contracted via feed-in tariffs respectively. ${ }^{15} \mathrm{MCE}$ has developed a $100 \%$ local solar product with a fixed rate that is directly tied to their feed-in tariff program (Gattaciecca, DeShazo, and Trumbull 2018). However, it should be noted that most CCAs outside California and Illinois have not emphasized local renewable energy procurement (see Figure 7). We discuss various challenges to local renewable energy procurement in Section 5.3.

CCAs may be well-positioned to offer additional energy services beyond electricity procurement. Most CCA interviewees reported that their CCAs were exploring additional services such as demand response, energy efficiency, and electric vehicle charging programs. At least four CCAs

\footnotetext{
${ }^{14} \mathrm{MCE}$ is a CCA that began in Marin County, California, and is formerly known as Marin Clean Energy. As MCE expanded to encompass multiple counties, the CCA switched its name to simply MCE.

${ }^{15}$ For context, the expected output of this capacity equates to less than $1 \%$ of the load of the two CCAs.
} 
in California offer electric vehicle incentives. These additional potential CCA services and customer incentives are outside the scope of this report but are ripe areas for further research.

\subsection{CCA Green Power Market Potential}

As a result of opt-out structures, competitive rates, and local control, CCAs could increase demand for voluntary green power in the United States. In this section, we estimate the potential impact of CCA expansion on voluntary green power demand. We estimate the share of electricity load that could be served by CCAs in the near future based on which states are more likely to pass CCA-enabling legislation. Based on that share, we estimate potential voluntary green power sales through CCAs based on historic CCA uptake of voluntary green power. We perform this exercise to provide an estimate of the extent to which CCA expansion could affect future electricity portfolios.

Before proceeding to the analysis, it is important to make three clarifications. First, our estimates reflect a range of potential rather than projected outcomes. In other words, we estimate how CCAs could affect voluntary green power demand under a range of policy assumptions that could facilitate further CCA expansion. Second, we assume that not all communities choose to implement voluntary green power CCAs in states with enabling legislation. In other words, our final estimates do not reflect the full technical potential of CCA voluntary green power, but rather a potential impact assuming that communities implement voluntary green power CCAs at rates similar to those observed to date. Third, an increase in the demand for voluntary green power does not necessarily translate to a one-to-one increase in the supply of renewable energy, because some voluntary green power may be sourced from existing projects or projects that would have been built anyway. We briefly discuss the potential impacts of CCAs on renewable energy supply, but further modeling-based analyses would be necessary for a more robust estimate.

As a first step, we identify the states that are most likely to have CCA-enabling legislation in the near future. We refer to the eight states that already have CCA-enabling legislation as Tier 1. According to LEAN Energy U.S. (2018), seven additional states have considered implementing CCA-enabling legislation: Colorado, Connecticut, New Hampshire, New Mexico, Nevada, Oregon, and Utah. There is also emerging interest in Arizona. For the time being, CCA talks in Colorado, New Mexico, and Utah appear to have stalled as the states have proposed legislation allowing communities to collaborate with investor-owned utilities as an alternative to CCAs. ${ }^{16}$ We therefore exclude Colorado, New Mexico, and Utah from our analysis, and we refer to the remaining four states $(\mathrm{CT}, \mathrm{NH}, \mathrm{NV}, \mathrm{OR})$ that have proposed or are considering CCA legislation as Tier 2 . See the appendix for more information about related policy initiatives in these states.

The Tier 1 and Tier 2 states share some notable traits. Most of these states have restructured retail electricity markets (Connecticut, Illinois, Massachusetts, New Hampshire, New Jersey, New York, Ohio, and Rhode Island), and the remaining states (California, Nevada, ${ }^{17}$ Oregon, and Virginia) allow retail competition for some large customers. This suggests that CCAs may

\footnotetext{
${ }^{16}$ In Colorado, see H.B. 1428 2018, “Authorize Utility Community Collaboration Contract.” In New Mexico, see S.B. 352 (2015).

${ }^{17}$ As of the publication of this report, Nevada is poised to pass a public ballot initiative moving the state to a fully restructured electricity market.
} 
be more feasible, at least in the near term, in states that already have some degree of retail electricity competition. We therefore assume other states with partially or fully restructured electricity markets are more likely to pass CCA-enabling legislation than states with regulated markets. The remaining states with restructured markets not included in Tier 1 or Tier 2 are Delaware, Michigan, ${ }^{18}$ Maine, Maryland, Pennsylvania, and Texas. We refer to these states as Tier 3 (Figure 9).

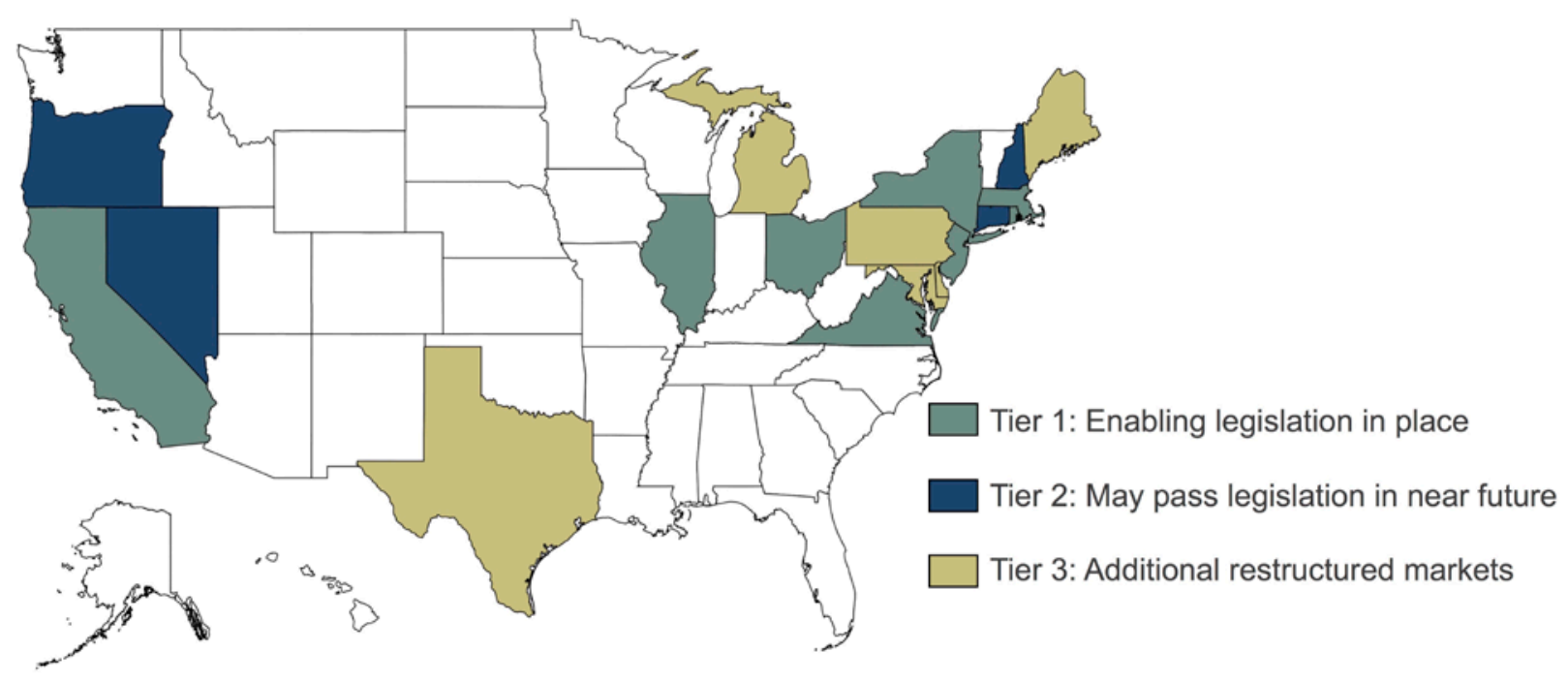

Figure 9. States most likely to soon have CCA-enabling legislation

Next, using EIA data (EIA 2016a), we estimate the total number of customers and sales (MWh) in each state served by investor-owned utilities or existing CCAs (i.e., excluding load served by municipal utilities and competitive suppliers). Table 5 reports the total "CCA-eligible" residential and commercial load in each of the tiers.

Table 5. CCA-Eligible Load (Load Currently Served by Investor-Owned Utility or CCA), Based on 2016 Data

\begin{tabular}{ccccc}
\hline \multirow{2}{*}{ Tier } & \multicolumn{2}{c}{ Sales (million MWh) } & \multicolumn{2}{c}{ Customers (millions) } \\
& Residential & Commercial & Residential & Commercial \\
\hline 1 & 308 & 361 & 38 & 4.1 \\
2 & 41 & 36 & 4 & 0.5 \\
3 & 129 & 108 & 13 & 1.0 \\
\hline
\end{tabular}

The CCA-eligible load represents an approximation of CCA sales if all communities within the tiers chose to aggregate. In other words, if all eligible communities in Tier 1, 2, and 3 states passed CCAs, CCAs could serve as much as 983 million MWh worth of residential and commercial load, or about $20 \%$ of all residential and commercial load in the United States. A expansion of that extent could affect grid-wide electricity portfolios, especially if CCAs pursue low-cost resources like natural gas or if some CCAs demand voluntary green power. However, there are numerous reasons some communities would not pursue CCAs and additional reasons

\footnotetext{
${ }^{18}$ Participation in competitive retail electricity markets in Michigan is capped and is at capacity in several service territories.
} 
communities would not pursue voluntary green power CCAs specifically. Based on feedback from our interviews, we identify prevailing electricity rates and renewable energy targets as two key motivating factors in determining CCA voluntary green power formation. CCAs and voluntary green power may be more attractive to communities and customers in states with higher basic service rates (see Section 4.2). Furthermore, cities with renewable energy targets may be more likely to pursue voluntary green power CCAs as a way to achieve $100 \%$ renewable energy procurement. At least 70 cities have 100\% renewable energy targets in the United States (Sierra Club 2018). Thirty-four of these jurisdictions are in one of the states in our analysis and are not currently served by a municipal utility.

We estimate the potential impacts of CCAs on voluntary green power demand under three scenarios based on which states enact CCA-enabling legislation (Table 6). We vary our assumptions about CCA implementation rates based on average state-level residential electricity rates, defining "high-cost" states as state with rates above $\$ 0.14 / \mathrm{kWh}$ and all other states as "low-cost" states. ${ }^{19}$ For two of the three scenarios, we limit CCA implementation to residential customers given that CCAs to date have primarily served residential load.

Table 6. CCA Green Power Demand Projection Assumptions

\begin{tabular}{|c|c|c|c|}
\hline Scenario & $\begin{array}{l}\text { States with } \\
\text { Enabling } \\
\text { Legislation }\end{array}$ & $\begin{array}{l}\text { CCA Voluntary Green Power } \\
\text { Market Share in Low-Cost States }\end{array}$ & $\begin{array}{l}\text { CCA Voluntary Green Power } \\
\text { Market Share in High-Cost } \\
\text { States }\end{array}$ \\
\hline \multirow{2}{*}{$\begin{array}{l}\text { Minimal } \\
\text { Expansion }\end{array}$} & \multirow[t]{2}{*}{ Tier 1} & - $10 \%$ of eligible residential sales & - $20 \%$ of eligible residential sales \\
\hline & & $\begin{array}{l}\text { - } 20 \% \text { of eligible residential } \\
\text { customers }\end{array}$ & $\begin{array}{l}\text { - } 40 \% \text { of eligible residential } \\
\text { customers }\end{array}$ \\
\hline \multirow[t]{2}{*}{ Expansion } & \multirow{2}{*}{$\begin{array}{l}\text { Tiers } 1 \\
\text { and } 2\end{array}$} & - $10 \%$ of eligible residential sales & - $20 \%$ of eligible residential sales \\
\hline & & $\begin{array}{l}\text { - } 20 \% \text { of eligible residential } \\
\text { customers }\end{array}$ & $\begin{array}{l}\text { - } 40 \% \text { of eligible residential } \\
\text { customers }\end{array}$ \\
\hline \multirow{3}{*}{$\begin{array}{l}\text { High } \\
\text { Expansion }\end{array}$} & \multirow{3}{*}{$\begin{array}{l}\text { Tiers } 1,2 \text {, } \\
\text { and } 3\end{array}$} & - $10 \%$ of eligible residential sales & - $10 \%$ of eligible residential sales \\
\hline & & $\begin{array}{l}\text { - } 20 \% \text { of eligible residential } \\
\text { customers }\end{array}$ & $\begin{array}{l}\text { - } 20 \% \text { of eligible residential } \\
\text { customers }\end{array}$ \\
\hline & & $\begin{array}{l}\text { - } 85 \% \text { of eligible } \\
\text { residential/commercial sales and } \\
\text { customers in cities with } 100 \% \\
\text { renewable energy targets }\end{array}$ & $\begin{array}{l}\text { - } 85 \% \text { of eligible } \\
\text { residential/commercial sales and } \\
\text { customers in cities with } 100 \% \\
\text { renewable energy targets }\end{array}$ \\
\hline
\end{tabular}

${ }^{*}$ For comparison, in 2017 , voluntary green power accounted for about $21 \%$ of all CCA sales and $45 \%$ of CCA customers.

Figure 10 presents the results of our analysis. For reference the figure also displays current estimates of voluntary green power CCA demand. The estimated impacts of the expansion of CCAs on voluntary green power demand range from 25 million MWh and 11 million customers in the Minimal Expansion scenario to 62 million MWh and 18 million customers in the High Expansion scenario. For context, about three million customers procured about 87 million MWh

\footnotetext{
${ }^{19}$ State-level residential rates are based on data from EIA (2018b). \$0.14/kWh represents roughly the median rate among the states in our analysis.
} 
of voluntary green power in 2016 outside of CCAs. CCAs have already increased voluntary green power demand by about $10 \%$ in terms of sales and have roughly doubled voluntary green power demand in terms of customers. Under our estimates, CCAs could increase voluntary green power demand by up to $65 \%$ in terms of sales, and by up to a factor of six in terms of customers relative to 2016 levels. ${ }^{20}$

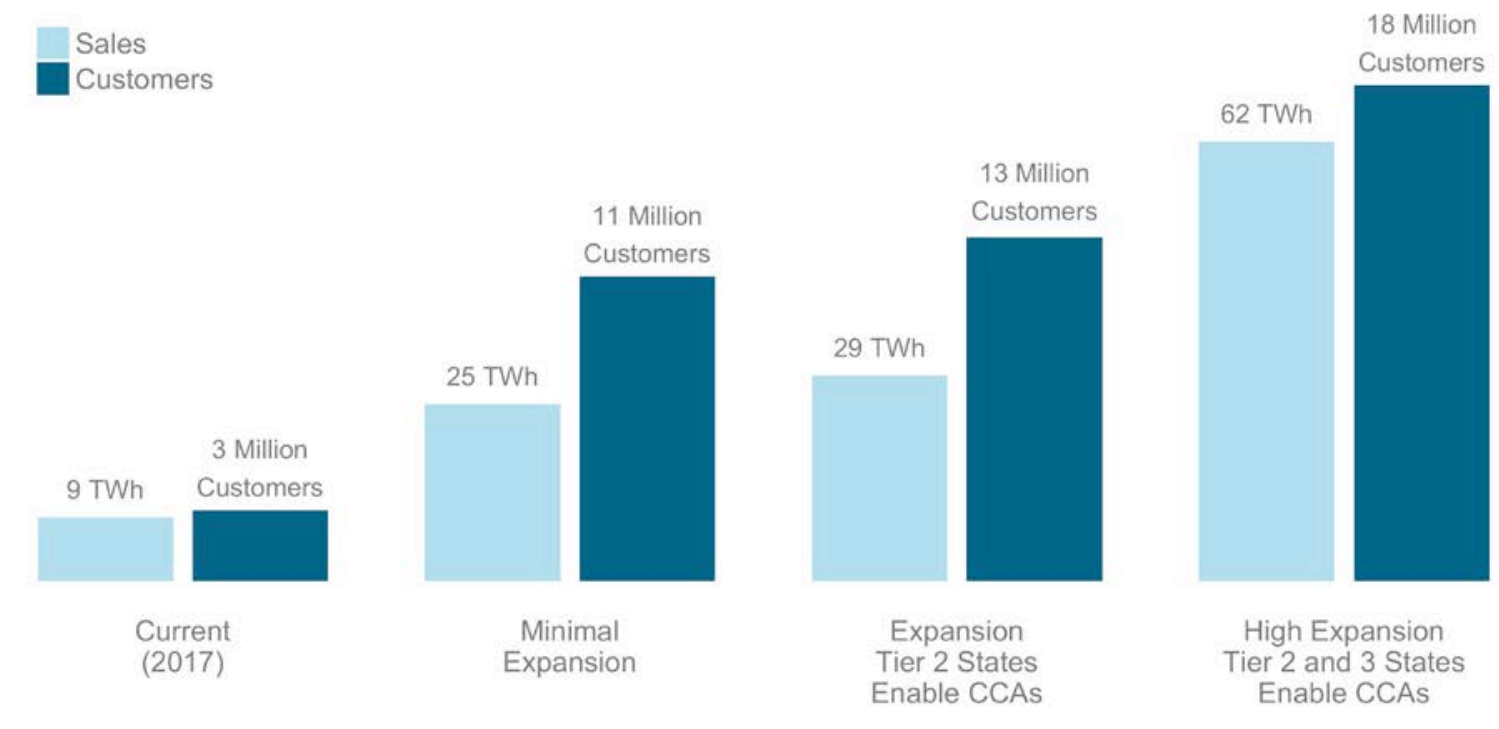

Figure 10. Estimated voluntary green power sales and participation under three scenarios $1 \mathrm{TWh}=1$ million MWh.

A CCA expansion could have both direct and indirect effects that could increase renewable energy supply. CCAs that decide to procure local renewable energy from new projects could have direct impacts on renewable energy supply. Especially in regulated or partially restructured markets, CCAs may indeed be required to procure new renewable energy capacity, and California CCAs have already demonstrated an ability to increase renewable energy supply through long-term contracts with new local generators (see Section 5.3). Furthermore, an influx of up to 56 million MWh of new voluntary green power demand could increase REC prices and send market signals that could indirectly result in new installed renewable energy capacity. Analysis of the relationship between CCAs and new renewable energy supply is an area for future research.

\footnotetext{
${ }^{20}$ Two key limitations should be noted. (1) Our analysis does not account for potential interactions between CCAs and other voluntary green power programs, such as utility green pricing. For instance, some current utility green pricing customers may switch to a CCA voluntary green power program, which would have no net effect on voluntary green power sales. (2) State RPSs may increase, which could reduce the voluntary green power content of CCA electricity portfolios.
} 


\section{Challenges and Opportunities}

In the preceding sections, we show that CCAs have grown considerably in the past decade (see Figure 5) and that future CCA expansion could drive significant increases in voluntary green power demand. However, the future expansion of CCAs could be stymied by various challenges. In this section, we identify and summarize six challenges facing the expansion of CCAs in general and three challenges facing the expansion of CCAs in regulated markets in particular. These challenges are based primarily on a series of 12 interviews with individuals involved with CCAs and CCA-focused organizations, and with other stakeholders. We also aim to identify opportunities to address these challenges.

\subsection{Maintaining Cost Savings}

All CCA interviewees stated that the ability to offer electricity cost savings to customers is critical for the ongoing viability of CCAs. Sustained periods of high CCA rates can lead to customer opt out and undermine CCA viability. Furthermore, sustained periods of high CCA rates can undermine the ability of CCAs to offer voluntary green power products. CCA rates may therefore need to be low enough to reduce or prevent opt out but high enough to recoup generation procurement and program administrative costs. ${ }^{21}$

The Illinois CCA market illustrates the importance of maintaining cost savings. From 2010 to 2013, relatively high basic service rates allowed Illinois CCAs to offer cost savings as high as $\$ 0.03 / \mathrm{kWh}$ (LEAN Energy U.S. 2018). As a result, CCA default and voluntary green power sales surged, peaking at about 25 million MWh in 2014 (Figure 11). CCAs lost their competitive edge as basic service rates fell from 2012 to 2014. Many communities chose to suspend CCAs and sales declined from 2014 through 2017. Beginning in 2013, several CCAs discontinued voluntary green power programs that could no longer be offered at a discount to basic service, and Illinois voluntary green power sales have since stagnated. Basic service rates have since increased and CCA participation may rebound in response, with 490 communities pending CCA implementation or reimplementation in 2018 (ICC 2018a), however it is still unclear whether voluntary green power sales will also rebound.

\footnotetext{
${ }^{21}$ Transmission and distribution remain the responsibility of the local utility. Utilities recoup these costs through
} separate transmission and distribution rates. 


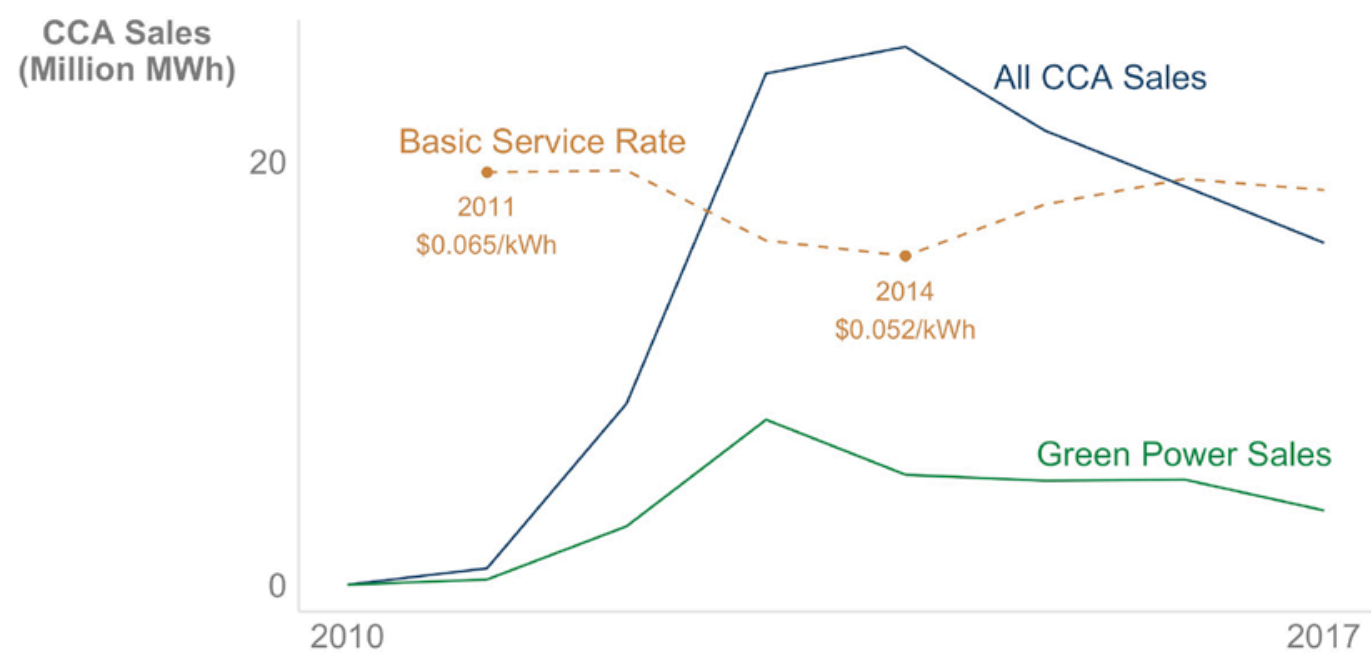

Figure 11. Illinois CCA sales and basic service rates, 2010-2017

CCA sales data were compiled from ICC (2018a); incumbent rate data were compiled from ICC (2018b).

Local electricity market and regulatory conditions can create challenges and opportunities for maintaining cost-competitiveness. Examples include:

- Energy price volatility poses risks to CCAs that lock into fixed-rate contracts. If local energy prices happen to fall, even temporarily, during a CCA contract term, some customers may opt out rather than remain in the program. For instance, energy prices have been gradually declining in Ohio. As a result of declining energy prices, a fixed price CCA rate becomes less cost-competitive over the course of the contract term. The City of Cincinnati CCA addressed this problem by negotiating three-year contract terms with rates that decline over time in line with projected energy price reductions. This challenge may be amplified in California, as legislation (SB 350) requires all loadserving entities - including CCAs - to procure $65 \%$ of their RPS-compliant renewable energy through contracts longer than 10 years, beginning in 2021. However, it is worth noting that most CCA interviewees reported that customers generally do not react to short-term price increases that temporarily cause CCA rates to exceed basic service rates.

- Volatile capacity markets can pose unique risks to CCAs. For instance, in Massachusetts, capacity costs are set in three separate load zones. Utilities that operate in multiple load zones can recoup capacity cost increases in one region through rate increases in all three regions, effectively hedging for their customers against capacity market volatility. In contrast, CCAs in a single region are fully exposed to the capacity market volatility in that region (Lichtenstein and Reid-Shaw n.d.). In 2017, the CCA in Melrose, Massachusetts, decided to suspend its program when capacity prices spiked in the region. The Cape Light Compact CCA in the Cape Cod region addresses capacity market volatility by negotiating new rates every three or six months, depending on customer class, to align with the timing of the utility rate changes. More frequent contract renegotiation prevents Cape Light Compact from locking into a long-term contract during a period of high capacity costs.

- In regulated markets, CCA rates may need to integrate "exit fees"- charges levied on customers that switch out of basic service. In theory, exit fees can be designed so that the 
fee reflects the true costs of the sunk utility investments made on behalf of CCA customers. However, setting optimal exit fees could be a controversial and politically fraught process that could artificially inflate or diminish the cost-competitiveness of CCAs. We discuss the case of exit fees in California in depth in Section 5.7.1.

Several CCA interviewees reported a willingness to discontinue voluntary green power products if voluntary green power could no longer be offered at a discount relative to basic service. Developing a cost-competitive voluntary green power product can be challenging, particularly given customer interest in costlier local renewable energy and especially local solar. However, CCAs have found various ways to increase the cost-competitiveness of voluntary green power products:

- CCAs can offer a lower-cost default product that focuses on being less expensive than competitor's rates, and a voluntary opt-up product with higher voluntary green power content. For instance, in California, most CCAs offer electricity portfolios with around $50 \%$ renewable energy by default and offer opt-up $100 \%$ renewable energy products.

- CCAs can enroll customers in a default opt-out voluntary green power product but allow them to opt down to a lower-cost product. An opt-down structure may allow CCAs to achieve high rates of voluntary green power sales through the opt-out voluntary green power product while still allowing customers the option to opt down to a lower cost product without opting out. For instance, customers in the Town of Portola Valley, a member of the Peninsula Clean Energy CCA in California, are automatically enrolled into a $100 \%$ renewable energy product but have the option to opt down to a product with $50 \%$ renewable energy at a lower rate. As of 2017 , about $4 \%$ of customers had elected to opt down and 5\% had opted out of the program entirely (Gattaciecca, DeShazo, and Trumbull 2017).

- In Massachusetts, Cape Light Compact developed a novel structure to offer costcompetitive voluntary green power that also supports regional renewable energy projects. Cape Light Compact offers a voluntary green power product comprising $1 \%$ in-state renewables coupled with $99 \%$ unbundled RECs procured outside Massachusetts - a structure used by other CCAs. Through its supplier, the Compact puts all revenues from the premiums on the unbundled RECs into a third party-administered trust fund. The trust fund will be used to fund future renewable energy projects, with an emphasis on projects to be built in the Northeast (Lichtenstein and Reid-Shaw n.d.). The relatively low cost of the unbundled RECs allows the Compact to continue to offer electricity rates that beat basic service. At the same time, the trust fund allows the Compact to support regional renewable energy development. However, this arrangement poses challenges of its own. It is important for CCAs that offer mixed electricity portfolios of local or regional renewables and unbundled RECs to clearly explain these products to their customers and not market such products as strictly "local." We further discuss challenges associated with customer awareness in Section 5.4.

A final issue related to maintaining cost-competitiveness is how CCAs incorporate low-income customers on subsidized basic service rates. Additional policies may be necessary to ensure lowincome customers continue to pay lower rates when switching to a CCA. One option is to simply exclude low-income customers from CCA enrollment if the CCA rate is higher than the lowincome basic service rate. Another option is to tie the subsidy to the customer's transmission and 
distribution fees, so that the subsidy travels with the customer. For instance, in California, certain low-income customers are eligible for subsidized rates under the California Alternate Rates for Energy (CARE) program. CARE benefits are tied to the transmission and distribution portion of a customer's bill, ensuring the customer does not lose the CARE benefits when switching to a CCA. CCAs can also design and set their own rates and may choose to offer special low-income rate products.

\subsection{Balancing Local Autonomy and Regional Cooperation}

The ability to exercise local choice and control over power procurement is a primary selling point of CCAs among policymakers. The benefits of autonomy have motivated many CCAs to aggregate at the city level, especially in Illinois, Massachusetts, and Ohio. However, individual communities may not have the resources or the legal, energy market, and regulatory expertise to successfully administer a CCA. Furthermore, there may be additional benefits to aggregating at larger geographic levels, such as the ability of large programs to offer additional services and leverage economies of scale. The benefits of having a larger CCA and serving more customers have motivated others to aggregate across multiple cities or counties, particularly in California. And, communities can increase regional cooperation in CCAs in at least two ways: through intergovernmental agreements and by working with nonprofits and trade organizations.

\subsubsection{Intergovernmental Agreements}

An intergovernmental agreement (IGA) is a contractual arrangement between multiple jurisdictions to provide a particular service. All the jurisdictions under an IGA have some representation through a board with oversight of the IGA. In the context of CCAs, a joint powers agreement (JPA) is a common IGA in which jurisdictions grant powers to a designated entity to perform specific services on behalf of the jurisdictions. In California, most CCAs launch through JPAs. For example, Sonoma Clean Power is a CCA in Sonoma and Mendocino Counties that operates under a JPA. Under the terms of the JPA, Sonoma Clean Power is authorized to procure energy on behalf of numerous jurisdictions across these counties. Examples of CCAs operating under IGAs outside California include Cape Light Compact in Massachusetts, Sustainable Westchester in New York, the Northeast Ohio Public Energy Council, and the Rhode Island Energy Aggregation Program.

The IGA structure has several potentially beneficial traits. First, IGAs enable greater economies of scale, allowing CCAs to generate sufficient revenue to fund staff who can manage administrative, advocacy, and business tasks (Gattaciecca, DeShazo, and Trumbull 2017). CCAs with IGAs may leverage these economies of scale to offer complementary energy programs and economic development projects (e.g., community solar, energy efficiency, electric vehicle charging, and microgrids) that may be cost-prohibitive for individual consumers or communities on their own. Second, IGAs allow CCAs to more easily expand geographically over time. For instance, Sonoma Clean Power integrated neighboring Mendocino County into its CCA in 2017 through a simple amendment to its existing JPA. The ability for expansion may allow existing CCAs to enhance economies of scale by collaborating with neighboring communities. Finally, IGAs create a legal and financial "firewall" between the assets and expenditures of the CCA and those of its member agencies, creating an extra layer of risk mitigation between the city and the CCA. Thus, communities that have yet to aggregate may benefit from the ability to join existing CCAs under the terms of an IGA. 
IGAs, however, present their own set of challenges. First, communities in an IGA lose some autonomy in energy procurement because they are procuring as a larger set of communities. However, interviewees did not identify this loss of autonomy as a significant challenge, as most of the time IGA members within a given county or region have similar goals (Gattaciecca, DeShazo, and Trumbull 2017). An interviewee at Redwood Coast Energy Authority reported that discord was rare in decision-making among the municipalities under the CCA, and that board decisions were frequently unanimous. Other CCAs opted for a hybrid version of JPA. An example of a hybrid JPA is the California Choice Energy Authority, led by the board members of Lancaster Choice Energy. In this hybrid JPA, any new joining city, such as Pico Rivera Innovative Municipal Energy becomes a new member of the Redwood Coast Energy Authority but does not obtain a seat at the board of the JPA. The Authority administers RFPs on other members' behalf. Though it does not control the RFP directly, Pico Rivera reported that the process for requesting specific outcomes from the RFP is straightforward and that the CCA typically can accommodate Pico Rivera's requests for specific electricity portfolios.

Second, the benefits of participating in a coordinated CCA may be imbalanced to favor certain jurisdictions depending on board representation and contract structures. According to several interviewees, while smaller communities that join an IGA may benefit from economies of scale, larger communities may not receive any price benefit and may end up subsidizing smaller jurisdictions. Furthermore, equitable board voting structures can be difficult to achieve in IGAs with communities of different sizes. Small communities will generally benefit from a one-voteper-community structure, while large communities will benefit from a voting structure weighted according to population. Redwood Coast Energy Authority devised a compromise in which onethird of CCA governance is determined by each board member's vote, and two-thirds of governance is determined in proportion to the number of electricity customers represented by each member. Several other CCAs in California use this type of mixed-weight voting system to create desired balance.

Finally, establishing an IGA can be a time- and legal-intensive process that may prove costprohibitive or too complex for smaller CCAs with limited resources and staff. One approach to surmount establishment challenges is to leverage pre-existing organizations to organize IGAs, such as local energy nonprofits, energy efficiency initiatives, and Solarize programs. ${ }^{22}$ For instance, the Cape Light Compact, Westchester Power, and Redwood Coast Energy Authority CCAs are all administered by organizations that predate the CCAs. These organizations offered existing expertise and relationships with local communities that allowed them to gain buy-in from municipalities to pursue CCA formation.

\subsubsection{Working with Non-Profits and Trade Organizations}

IGAs allow for joint procurement of electricity supply across multiple communities within a CCA. An additional model is to facilitate cooperation across multiple CCAs through a nonprofit or trade organization. To our knowledge, state-level CCA organizations only exist in California and Massachusetts, and LEAN Energy U.S. has emerged as a national-level CCA-focused organization.

\footnotetext{
22 In a Solarize campaign, a community group negotiates with PV installers on behalf of the community's residents. Through bulk purchasing, Solarize campaigns can help customers obtain lower prices for rooftop PV systems.
} 
In California, the trade organization California Community Choice Association (CalCCA) currently works on behalf of 18 member CCAs. It lobbies on key CCA policy issues in California, including CCA procurement autonomy, support of CCA growth, and exit fees (see Section 5.7). CalCCA member CCAs interact with each other through numerous thematic committees, including a regulatory committee, a marketing committee, and a procurement committee. Several interviewees stated that CalCCA played a key role in the growth of California CCAs. Small CCAs, in particular, benefit from the ability to draw on regulatory resources from CalCCA that may be cost-prohibitive to bring in house.

In Massachusetts, the Green Energy Consumers Alliance (formerly known as the Mass Energy Consumers Alliance) is a nonprofit organization administering multiple energy and sustainability programs. In 2017, the Alliance began assisting CCAs with renewable energy procurement. The Alliance facilitates REC sales between CCA suppliers and in-state renewable energy projects, primarily from wind. Because Green Energy Consumers Alliance is a nonprofit, the voluntary green power portion of CCA customer electricity bills is tax-deductible, effectively lowering voluntary green power premiums for CCAs that use the Alliance's services. The Alliance also provides various educational services to CCAs, and it plans to offer additional services such as electric vehicle charging programs and rooftop solar programs in the future.

At the national level, LEAN Energy U.S. provides a variety of services to CCAs and policymakers, including outreach, consulting during program development, and consulting on regulatory and legislative affairs. LEAN Energy U.S. also serves as a CCA information clearinghouse, providing educational materials about CCAs and tracking CCA policy developments in states with enabling legislation and states that are considering CCA policies.

\subsection{Local Renewable Energy Procurement}

All CCA interviewees reported high levels of CCA and customer interest in local renewable energy and local solar in particular. Meeting demands for local renewable energy poses particular challenges to CCAs that vary across restructured and regulated markets.

In restructured markets, CCAs procure electricity through competitive suppliers, and thus must work through their suppliers to procure local renewable energy. The ability of CCAs to procure local renewable energy can be restricted by state policies on contract lengths. For instance, CCAs in Ohio are restricted to signing supply contracts of no more than three years. CCA procurement of short-term contracts reduces the ability of competitive suppliers to procure long-term contracts for local renewables on behalf of CCAs in Ohio and other restructured market states. As a result, CCAs in these states have relied on short-term unbundled REC purchases to supply their voluntary green power portfolios. CCA interviewees from restructured markets did not identify clear pathways to increase local renewable energy procurement.

On the other hand, California CCAs can enter into long-term contracts with local renewable energy developers. Indeed, by 2021, CCAs and all other California load-serving entities are required by statute to procure at least $65 \%$ of their RPS-compliant renewable energy through either contracts of longer than 10 years or CCA-owned resources. Long-term contracts provide the opportunity for CCAs to (1) participate, either as a project sponsor or power offtaker, in the construction of new renewable energy facilities and (2) benefit from historically low renewable energy prices. However, the push for local renewable energy is creating pressure for CCAs to 
find ways to finance these long-term contracts. Some California CCAs are seeking credit ratings in order to obtain low-cost financing. In 2018, MCE became the first CCA to obtain an investment grade credit rating, suggesting that other CCAs may be able to pursue a similar path. One California CCA interviewee suggested that financing did not present a major hurdle to CCAs as long as the CCA had a healthy financial standing and significant reserves. In fact, Sonoma Clean Power and Lancaster Choice Energy procured 32\% and 14\% of their RPScompliant renewable energy in 2017 through long-term contracts, respectively, despite not having a credit rating (Gattaciecca, DeShazo, and Trumbull 2018).

Several CCA interviewees expressed interest in offering community solar as a means of procuring local solar. In the community solar model, a group of customers "subscribe" to the output of a single shared solar PV project. Community solar is growing rapidly around the country, due to strong customer interest and favorable incentives, among other factors (O'Shaughnessy, Heeter, and Sauer 2018). To our knowledge, MCE in California is the only CCA to have implemented a community solar project, to date. The MCE Local Sol program offers CCA customers the opportunity to subscribe to shares of a 1-MW PV array. Westchester Power in New York is also exploring how to integrate community solar into its electricity portfolio. But there are several models through which CCAs may use community solar to support local solar development:

- CCA-wide community solar: A CCA could develop a community solar project and automatically enroll all customers. Community solar bill credits and RECs could be evenly distributed to all CCA customers. An opt-out community solar model has not been tested, and it is unclear whether such a model could attract the project financing needed to support community solar deployment.

- Opt-in community solar: A CCA could develop a community solar project and allow CCA customers to opt into the project. Community solar bill credits and RECs could be distributed to the subscribers only. This is the model for MCE's Local Sol community solar program.

- Neighborhood community solar: For larger CCAs, the CCA could facilitate community solar development at the neighborhood level. This structure could partition the CCA into neighborhood blocks and automatically enroll residents within specific blocks into community solar projects.

\subsection{Customer Awareness}

Most retail electricity customers, particularly residential customers, have a limited understanding of their electricity supply. According to CCA interviewees, most customers have a similarly basic understanding of aggregation and its implications for customers. Indeed, CCA interviewees report that most customers are largely unaware that any change has occurred after CCA implementation, even if the CCA mails multiple notices and engages in a robust community outreach campaign.

Lack of customer awareness can pose challenges to CCAs for several reasons. Lack of customer awareness creates opportunities for misunderstanding and misinformation. Particularly in California, where regulatory proceedings concerning exit fees and other policy decisions have made CCAs more publicly salient, stakeholder interviewees stated that misunderstandings and 
misinformation could undermine future CCA growth. Lack of customer awareness can affect customer opt-out rates. Several CCA interviewees reported that some customers immediately opt out of the program, before realizing the CCA offered lower rates than basic service and opting back into the CCA. Trade organizations like CalCCA and other CCA-focused organizations can play a key role in increasing customer awareness of the accurate benefits and costs of CCA participation.

In restructured markets, lack of customer awareness could lead customers to equate CCAs with competitive suppliers. This association could burden CCAs with some of the reputational baggage of competitive suppliers. A 2018 report commissioned by the Massachusetts Attorney General's Office (Baldwin 2018) found that competitive supplier rates were generally higher than basic service rates. The report detailed unfair and deceptive practices reported by customers and notes that low-income customers may be particularly adversely affected by competitive supplier tactics. Similar issues have been identified with competitive suppliers in other states. CCA interviewees expressed concern that customers' and policymakers' perceptions of competitive suppliers could affect future prospects for CCAs. Declining public trust in competitive suppliers may also present an opportunity for CCAs; by negotiating with suppliers on behalf of retail customers, CCAs may offer increased customer protection in restructured electricity markets. However, it is important to note that some customers may prefer to work directly with competitive suppliers and continue to have the option to do so after CCA formation. Furthermore, like CCAs, competitive suppliers have been key actors in U.S. voluntary green power markets, selling around 18 million MWh of voluntary green power in 2017

(O’Shaughnessy, Heeter, and Sauer 2018).

Lack of customer awareness poses unique challenges to CCAs that offer voluntary green power products. CCAs that offer opt-out voluntary green power products may face challenges in describing the products in ways that customers can easily understand. Many CCAs use some mix of local, regional, and nationally sourced renewable energy in their voluntary green power products. These blended products create opportunities for customer confusion, especially given lack of customer familiarity with RECs. For instance, a common structure is a product composed of 1\% local renewables and $99 \%$ nationally sourced renewables, typically through unbundled wind RECs. This type of product could be opaque and possibly deceiving. Such a product could be marketed as "local" when in fact the electricity portfolio primarily comprises out-of-state renewable energy content. To ensure ongoing consumer confidence in CCAs, it is important for CCAs to clearly explain their electricity portfolios and the rationale behind procurement decisions. Some states, such as California, require CCAs and incumbent utilities to report power content to their customers at least annually.

To increase customer awareness, some CCAs dedicate resources to customer education. For instance, several CCAs in California have formed (1) community advisory committees to gather input from CCA customers and (2) dedicated marketing teams committed to customer education and outreach. Some CCAs, such as CalCCA in California and the Green Energy Consumers Alliance in Massachusetts work with third parties to enhance customer awareness. In particular, interviewees from CCAs that offer local voluntary green power products reported active customer education efforts to inform customers about renewable energy resources and the benefits of voluntary green power procurement. For instance, the Green Energy Consumers Alliance offers tours of wind turbine sites to CCA customers. However, not all CCAs prioritize 
customer education. Indeed, one CCA interviewee stated that excessive customer outreach can backfire if customers become weary of CCA correspondence and decide to opt out. A key challenge for CCAs is striking an optimal balance of customer awareness and acceptable levels of outreach.

\subsection{Customer Opt Out}

All active CCAs operate as opt-out programs. However, specific requirements for how customers are enrolled into CCAs and may opt out of CCAs vary according to state and CCA policies. Some of these policies pose challenges for CCAs to maintain a stable customer base.

State policies generally require a similar process for initial customer enrollment. During CCA implementation, new CCAs must provide multiple notices to customers that their electricity supply is being shifted to the CCA. CCAs are required to inform customers of their options and describe the process to opt out. CCAs are prohibited from charging customers any opt-out fees during the initial enrollment phase. In restructured markets, CCAs may be prohibited from enrolling customers that have already switched from basic service to a competitive supplier. In partially restructured markets, CCAs may similarly be prohibited from enrolling large nonresidential customers with direct access exemptions or they or choose not to do so. Some CCAs also reported excluding customers on low-income rates during CCA enrollment.

Policies vary in terms of how to treat new customers that move into the CCA service area:

- In California, move-in customers are automatically enrolled into the CCA. CCAs are required to provide at least two opt-out notices to move-in customers.

- In Illinois and Ohio, move-in customers are automatically enrolled onto utility basic service. As a result, CCAs gradually lose load as customers move out and are replaced by move-in customers enrolled into basic service. This gradual customer turnover may be particularly common in urban areas with more transient populations. For instance, the City of Cincinnati CCA reports losing a few thousand customers per month due to customer move-outs.

- In Massachusetts, move-in customers are initially enrolled into basic service and provided notice about the CCA. Customers may be automatically enrolled into the CCA 30 days after receiving the notice.

CCAs address the issue of default enrollment of move-in customers into basic utility service by conducting periodic "sweeps" to enroll basic service customers into the CCA. During a sweep, move-in customers are automatically enrolled into a CCA and provided notices of opportunity to opt out. For instance, the City of Cincinnati conducts a sweep every six months to enroll new move-in customers (Figure 12, page 29). Sweeps introduce additional administrative and cost challenges that depend on who is responsible for conducting the sweeps. For CCAs that work directly with competitive suppliers, the supplier is responsible for the sweeps and may factor the cost of the sweeps into the electricity rate. In this case, the incentives of the competitive supplier align with those of the CCA; the supplier wants to enroll and serve as many customers as possible. For CCAs that contract with energy consultants, the consultant may conduct the sweeps and charge the CCA for the service. In this case, some interviewees reported that the incentives of the consultant do not necessarily align with those of the CCA; the consultant gets paid 
regardless of how many customers are swept into the CCA. In both cases, the requirement to conduct periodic sweeps increases program costs. It is unclear why the restructured market states do not follow the California model and automatically enroll move-in and competitive supplier customers into the CCAs.

In restructured markets, CCA customers may opt out in order to switch to other competitive suppliers, particularly if an alternative supplier can offer a lower rate than the CCA. If a CCA customer switches to a competitive supplier with a short-term offer, it may be unclear what happens to the customer after the contract has expired. In Massachusetts, for example, such customers are automatically shifted back to utility basic service at the end of their competitive supplier contract. As with move-in customers, these customers must be enrolled back into the CCA through periodic sweeps.

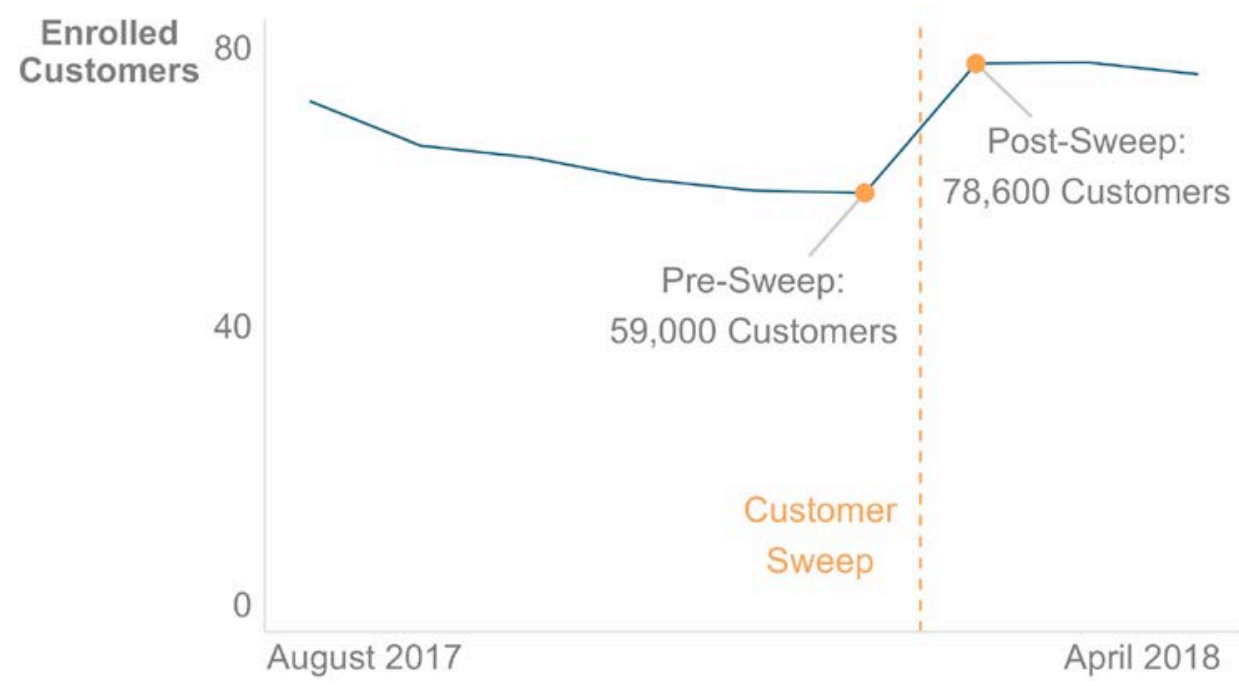

Figure 12. Number of enrolled customers in Cincinnati CCA before and after a customer sweep Source: Based on data provided by the City of Cincinnati (2018)

\subsection{Policies for CCA Suspension or Dissolution}

CCAs can suspend power supply to their customers or can disband entirely. In restructured markets, this process is theoretically straightforward. Policies in restructured markets stipulate that local utilities are providers of last resort, meaning utilities are obligated to serve customers that leave competitive suppliers. When a CCA suspends service or dissolves in a restructured market, customers are reverted onto the basic service of the local utility. To prevent load and cost volatility, some states require customers to remain with the utility for at least 12 months after switching from a competitive supplier.

The ability to suspend CCA service may be a useful feature in restructured markets, as it allows CCAs to flexibly respond to changes in basic service rates. For instance, a CCA may choose to suspend service if an RFP does not yield a competitive rate, in which case the CCA's customers could save money by reverting to basic service. A suspended CCA could potentially monitor basic service rates and issue a new RFP once supplier rates have become competitive again. However, the ability of CCAs to suspend and restart operations may need to be clearly delineated in enabling legislation. For instance, in Massachusetts, CCAs that stop serving customers, even 
temporarily, are currently required to dissolve the CCA entirely. Such requirements force CCAs to reincur start-up costs each time a CCA is dissolved and restarted. This type of policy may incentivize CCAs to remain active, even when a temporary suspension of the program could be more cost-effective for their customers.

The challenge of CCA suspension or dissolution is potentially more complicated in regulated markets such as California. Regulated markets may not have explicit policies stating that utilities are providers of last resort, as exist in restructured markets. In California, the California Public Utility Commission (CPUC) has opined that the state's utilities are the "presumed" providers of last resort (Colvin et al. 2018). However, the utilities have called on the CPUC to "re-examine" this assumption in light of declining utility load bases (PG\&E and SDG\&E 2018). These unresolved questions may create regulatory uncertainty for CCAs in regulated markets. Furthermore, CCAs in regulated markets may hold various long-term contracts for generation. In the event of a CCA bankruptcy or dissolution, additional policy mechanisms may need to be in place to ensure these contracts are transferable in a way that ensures ongoing grid reliability.

\subsection{Challenges in Regulated Markets}

California and Virginia are the only states with predominantly regulated retail electricity markets that currently allow CCAs, though several other regulated market states have considered enabling legislation (LEAN Energy U.S. 2018). The fact that no other regulated market states have implemented CCA-enabling legislation may indicate the considerable challenges facing CCAs in regulated markets, including but not limited to significant opposition from investorowned utilities. CCAs have expanded rapidly in California but have not been implemented in Virginia.

California restructured its electricity markets in the 1990s but suspended restructuring efforts following the energy crisis of 2001. As a result, California is unique among electricity markets: its investor-owned utilities primarily procure energy through long-term contracts with independent power producers; wholesale electricity markets remain deregulated; and some large non-residential customers may procure supply directly from non-utility providers (CPUC 2018a). CCAs in other regulated markets may face unique sets of challenges. However, at least two salient challenges facing California CCAs may be universal in regulated markets: problems associated with cost allocation and issues associated with resource adequacy.

\subsubsection{Legacy Cost Allocation}

In regulated markets, utilities have historically invested in generation and capacity on behalf of the customers in their service territories. Utilities recoup these investments through customer bill payments. When a CCA is formed, the utilities' ability to recover costs through customer electricity payments has diminished, but the sunk investments have not. As a result, CCA policies in regulated markets need to identify how utilities will be compensated for "legacy costs" when customers are enrolled into CCAs, similar to transition fees when electric markets have gone from regulated to restructured.

In California, legacy utility costs are recovered through a mechanism known as the power charge indifference adjustment (PCIA). The PCIA estimates the price difference between the average electricity portfolio cost of the investor-owned utility and the current market value of electricity, also called the market price benchmark (Gattaciecca, Trumbull, and DeShazo 2017). The PCIA 
was established as an interim solution when the amount of load that could potentially leave the utilities was capped. The PCIA methodology has been discussed and criticized by many stakeholders (CPUC 2018b). CCAs argue the PCIA suffers from high volatility and lack of transparency, predictability, accuracy, and efficacy (Gattaciecca, Trumbull, and DeShazo 2017). California investor-owned utilities have argued the existing PCIA is too low (PG\&E and SDG\&E 2018). An excessively low PCIA can result in cross-subsidization, where CCA customer rates are lower at the expense of customers that remain on basic utility service. PG\&E estimates that the current PCIA methodology results in an approximately \$200 million CCA cross-subsidization in its service territory (PG\&E and SDG\&E 2018). This dynamic can generate a positive feedback loop: as more customers move to CCAs, basic service rates have to increase to compensate for the under-estimated cost adjustment factored into the PCIA, thus incentivizing more communities to form CCAs. This feedback loop could pose a challenge to utilities facing load loss to CCAs as well as to utility customers in areas not served by CCAs.

The CPUC has recently proposed to revise the inputs used to calculate the market price benchmark (CPUC 2018b). The CPUC proposes an annual true-up mechanism and a cap to provide rate stability and predictability. The CPUC also opened a second phase of this proceeding to consider alternative solutions to address excess resources in utility electricity portfolios. The solution is expected to be based on a voluntary market-based redistribution of these resources in which CCAs are allowed to buy long-term contracts from the utilities. Through this structure, investor-owned utilities could be unburdened of long-term contracts that are no longer economical, and CCAs could be able to buy long-term contracts along with their non-energy attributes, including RECs and resource adequacy attributes. The voluntary transfer of uneconomical renewable energy long-term contracts could help CCAs comply with the RPS, resource adequacy requirements, and SB 350, while reducing the price level of the PCIA.

At the time of publication, the CPUC had recently ruled to increase PCIA rates by $1 \%$ to $5 \%$ depending on the service area. The impacts of the PCIA adjustment on the expansion of CCAs in California is still uncertain. At a minimum, the PCIA increase may affect California CCA rates.

\subsubsection{Resource Adequacy}

Resource adequacy refers to the ability of the generation resources on a grid to supply electricity during peak events. In regulated markets, utilities are required to demonstrate resource adequacy and can rate base investments in system capacity. CCA-enabling legislation may need to define the resource adequacy obligations of utilities and CCAs in regulated markets.

In California, all load-serving entities are subject to the three types of resource adequacy requirements: system resource adequacy (115\% of peak demand), local resource adequacy (in areas with transmission limitations), and flexible resource adequacy (ability to meet the largest three-hour continuous ramp) (CPUC 2017). These three types of resource adequacy requirements are in place to ensure all load-serving entities have the right amount and type of resources available to constantly meet demand, while addressing intermittency and ramping challenges resulting from higher penetrations of renewable energy, maintaining grid stability and reliability, and decreasing the need for long distance transmission lines (Gattaciecca, DeShazo, and Trumbull 2018). A recent CPUC report identified CCAs as one of several challenges to California resource adequacy (CPUC 2018a). Specifically, the CPUC found that new CCAs do not initially participate in the year-ahead resource adequacy process. The delayed entry of CCAs 
into the year-ahead resource adequacy process temporarily shifts resource adequacy obligations to the utilities until new CCAs file their implementation plans. See Gattaciecca, DeShazo, and Trumbull (2018) for further information on and analysis of California resource adequacy requirements.

\subsubsection{Public Utility Commission Jurisdiction and Fragmentation}

Utilities are regulated by state-level regulatory entities generally known as public utility commissions. State policymakers can enact state-level energy policy initiatives such as PV rebates and energy efficiency programs, which then are implemented by the utility commission (Colvin et al. 2018). CCAs in California have argued that, like municipal utilities, certain elements of utility commission jurisdiction do not extend to "new market actors" such as CCAs (CalCCA 2018b). ${ }^{23}$ If so, CCA formation reduces the jurisdictional reach of utility commissions over rate design, ratemaking, and some procurement decisions made by CCAs' board, which is composed of elected officials. The CPUC has referred to this phenomenon as "fragmentation" (Colvin et al. 2018). The potential implications of fragmentation remain uncertain in regulated electricity markets. At the very least, it is clear that fragmentation reduces state-level control over load-serving entities (Colvin et al. 2018; PG\&E and SDG\&E 2018).

Fragmentation could force utility commissions to reexamine regulations and the roles of investor-owned utilities and other load-serving entities, particularly with respect to resource procurement and resource adequacy (Colvin et al. 2018). However, it does not necessarily follow that fragmentation undermines state energy policy objectives. For instance, CalCCA (2018b) argues that California CCAs treat state renewable energy policies as "targets to meet or exceed." CCAs are required to comply with the state's resource adequacy and RPS requirements and submit integrated resource plans to the CPUC every two years for certification.

\footnotetext{
${ }^{23}$ In public comments, CalCCA states, "The [CPUC] is an agency of constitutional origin that is tasked with regulating the state's [investor-owned utilities]... It is critical that the CPUC continue to focus on this enormous task rather than seek expansion of its oversight function to new market actors in the absence of any clear need or consumer harm."
} 


\section{Conclusion}

CCAs could reshape U.S. electricity markets and electricity portfolios. Already, CCAs procure around 42 million MWh per year on behalf of about 5 million customers. CCAs may have already begun to reshape electricity portfolios by demanding more renewable energy than is required by state mandates. In 2017, we estimate that CCAs procured about 8.9 million MWh of renewable energy above and beyond levels required by state mandates. We estimate that an expansion of CCAs into more states could result in CCAs being responsible for as much as $20 \%$ of U.S. residential and commercial load and could increase demand for renewable energy by as much as 53 million MWh per year.

However, CCAs face various challenges and regulatory constraints. We identify six challenges facing CCAs in general and several challenges facing CCAs in regulated markets in particular:

- Maintaining cost savings: CCAs must find ways to offer competitive rates to their customers, otherwise customers may opt out in search of lower electricity prices. To date, CCAs have largely met this challenge, with most CCAs offering rates lower than utility rates.

- Balancing local autonomy and regional cooperation: Communities face tradeoffs between aggregating customers within a single jurisdiction (e.g., town level) versus aggregating across multiple jurisdictions (e.g., county level). Aggregating a single jurisdiction ensure high levels of autonomy over electricity supply and rates, while aggregating across jurisdictions can yield economies of scale and allow CCAs to offer more services. CCAs have used contractual structures such as joint powers agreements to aggregate across multiple jurisdictions, particularly in California. Some state- and national-level organizations have emerged to facilitate cooperation among CCAs.

- Local renewable energy procurement: All CCA interviewees expressed interest in increased procurement of local renewable energy. For CCAs in restructured electricity markets, inability to sign long-term contracts poses a challenge to local renewable energy procurement. However CCAs in restructured markets are exploring and implementing innovative ways to procure local renewables, such as through trust funds for local projects and community solar. In regulated electricity markets, CCAs are increasingly signing long-term contracts for local renewable energy, especially as CCAs mature and improve financial standing with creditors.

- Customer awareness: CCA is a new and relatively unknown concept. Interviewees reported that most CCA customers are unaware that any change has occurred in their electricity service. Interviewees reported that many CCAs and CCA organizations have implemented informational campaigns to increase customer awareness about CCAs and, in some cases, about CCA renewable energy procurement in particular.

- Customer enrollment: State-level policies determine how CCAs enroll customers that move into a CCA's service territory after CCA implementation. In certain states, move-in customers automatically enrolled into utility basic service rather than into the CCA. In these states, CCAs have addressed this issue by enrolling move-in customers through periodic "sweeps," though these sweeps may increase program costs. 
- Policies for CCA suspension or dissolution: Some communities have suspended or dissolved CCAs. The ability of communities to suspend CCAs may be beneficial in some cases, allowing communities to respond to changing market conditions in ways that benefit the community's residents. At the same time, CCA suspension or dissolution may undermine project developer and investor confidence in CCA investments.

- Challenges specific to regulated markets: California is the only regulated electricity market state with active CCAs. CCAs face challenges in California that are largely unique among the CCA states. California CCAs are required to pay fees designed to compensate utilities for sunk investments in long-term contracts signed on behalf of CCA customers, commonly known as exit fees. The determination of these fees can be contentious, as over- or under-estimation of the fees can favor utilities or CCAs, respectively. California CCAs are also subject to resource adequacy requirements that obligate CCAs to enter into long-term contracts. These and other issues are areas of ongoing discussion in California.

We have presented a rough initial estimate of the potential future expansion of CCAs and how that expansion could increase demand for voluntary green power. Ultimately, CCA adoption and voluntary green power procurement depends on numerous and often intangible local variables that preclude any accurate estimation of the potential impacts of CCAs. A more accurate assessment of the potential impacts of CCAs on electricity portfolios and renewable energy supply would require more complex modeling beyond the scope of our study. Future studies can build on our analysis to develop a broader set of characteristics that predict CCA expansion and voluntary green power adoption. We focused exclusively on impacts on renewable energy supply in electricity portfolios. Future research could analyze how CCAs may affect the prevalence of other non-renewable resources in electricity portfolios, such as natural gas, coal, and nuclear. Future work can explore the grid impacts of CCA expansion more generally, such as how CCA expansion could affect resource adequacy. Future work could further explore the changing roles of investor-owned utilities in areas with high levels of CCA penetration.

There remain unanswered questions concerning how CCAs may affect electricity markets and electricity portfolios in the United States. Regardless of the answers, CCAs are moving forward. The ongoing policy deliberations in California represent the early stages of stakeholders' attempts to address the challenges and opportunities created by CCAs. Integrating CCAs into electricity markets will require collaboration across a diverse set of stakeholders, including CCAs, utilities, public utility commissions, policymakers, customer advocates, and environmental groups. Our analysis is a first attempt to advance this collaboration and promote the responsible and effective integration of CCAs into electricity and voluntary green power markets across the United States. 


\section{Glossary}

Basic service: Electricity service provided by local utility. In the absence of a CCA, basic service is generally the customer's default service, so that customers are automatically enrolled into basic service if they do not choose otherwise.

Community choice aggregation: Local governmental entity that procures electricity on behalf of retail electricity customers within a certain geographic area.

Competitive supplier: Licensed load-serving entities that can compete with utilities to provide electricity generation services in restructured electricity markets.

Direct access: Provisions in regulated markets allowing certain customers to procure electricity generation from non-utility electricity service providers.

Electricity portfolio: The mix of resources used by a load-serving entity to generate and sell electricity to retail customers.

Opt out: Provision allowing CCAs to act as default providers of electricity. Customers may opt out of a CCA and return to basic service.

Regulated electricity market: Electricity market where regulated utilities are the only providers of transmission, distribution, and electricity generation services.

RPS (renewable portfolio standard): State policy requiring that utilities and other electricity generation service providers procure a minimum percentage of generation from renewable energy.

Restructured electricity market: Electricity market where non-utility entities (competitive suppliers) can compete with utilities to provide electricity generation services.

Voluntary green power: Renewable energy procurement in excess of an RPS. 


\section{References}

Aldy, J., M. Kotchen. 2012. "Willingness to pay and political support for a U.S. national clean energy standard." Nature Climate Change 2:596-599.

Baldwin, S. 2018. Are Consumers Benefiting from Competition? Massachusetts Attorney General's Office.

Binns, C. 2018. Community Choice Aggregation Informational Slide Deck. Joule Community Power.

Borenstein, S., and J. Bushnell. 2015. The U.S. Electricity Industry After 20 Years of Restructuring. NBER Working Paper 21113.

CalCCA. 2018a. Operational Member Profiles. Accessed August 6, 2018: https://calcca.org/cca-impact/.

CalCCA. 2018b. Comments on the Staff White Paper. June 11, 2018.

City of Cincinnati. 2018. Data set shared on August 13, 2018.

Colvin, M., D. Fellman, and R. Rodriguez. 2018. California Customer Choice. California Public Utilities Commission. Revised version 5-17-2018.

CPUC (California Public Utilities Commission). 2017. 2016 Resource Adequacy Report.

—.2018a. Current Trends in California's Resource Adequacy Program.

—.2018b. Proceeding to Allocate Customer CCA Costs.

Defeuilley, C. 2009. "Retail Competition in Electricity Markets.” Energy Policy 37:377-386.

EIA (U.S. Energy Information Administration). 2016a. Form EIA-861.

_.2016b. 2016 Average Monthly Bill-Residential.

- 2018a. Sales to Ultimate Customers (Megawatt Hours) by State by Sector by Provider, 1990-2016.

-2018b. Table 5.6.A. Average Price of Electricity to Ultimate Customers by End-Use Sector. May 2018.

Englum, L., K. Chatterjee, S. Marshall, L. Medearis, A. Ronen, and S. Wochos. 2014. Leading from the Middle. World Wildlife Fund.

Farhar, B. 1999. Willingness to Pay for Electricity from Renewable Resources: A Review of Utility Market Research. NREL/TP.550.26148. Golden, CO: NREL. 
Frederiks, E., K. Stenner, and E. Hobman. 2015. "Household Energy Use: Applying Behavioural Economics to Understand Consumer Decision-Making and Behaviour." Renewable and Sustainable Energy Reviews 41:1385-1394.

Gattaciecca, J. J.R. DeShazo, and K. Trumbull. 2017. Evaluating Community Choice Aggregation Alternatives for the City of Santa Monica. Luskin Center for Innovation, University of California Los Angeles (UCLA).

Gattaciecca, J., K. Trumbull, and J.R. DeShazo. 2017. The Promises and Challenges of Community Choice Aggregation in California. Luskin Center for Innovation, University of California Los Angeles (UCLA).

Gattaciecca, J. J.R. DeShazo, and K. Trumbull. 2018. The Growth in Community Choice Aggregation. Luskin Center for Innovation, University of California Los Angeles (UCLA).

Henderson, R. 2017. Community Choice Aggregation: How Far Can it Push Energy Sector Transformation? Smart Electric Power Alliance.

Homefield Energy. 2018. Communities We Serve. Accessed August 8, 2018: https://www.dynegy.com/homefield/municipal-aggregation/communities-we-serve.

ICC (Illinois Commerce Commission). 2018a. List of Communities Pursuing Opt-Out Municipal Aggregation Program. Accessed June 6, 2018:

https://www.pluginillinois.org/MunicipalAggregationList.aspx.

- 2018b. Historical Prices to Compare. Accessed June 6, 2018:

https://www.pluginillinois.org/fixedrate.aspx.

- 2018c. Electric Switching Statistics. Accessed June 6, 2018:

https://www.icc.illinois.gov/electricity/switchingstatistics.aspx.

J.D. Power. 2017. Overall Residential Electric Utility Customer Satisfaction Increases for Sixth Consecutive Year.

LEAN Energy U.S. 2018. http://www.leanenergyus.org/.

Lichtenstein, G., and I. Reid-Shaw. n.d. Community Choice Aggregation (CCA)

in Massachusetts. University of New Hampshire Sustainability Institute.

Lillian, B. 2018. "Boston Takes 'Big Step' Toward Community Choice Aggregation." North American Wind Power.

Ma, C., A. Rogers, M. Kragt, F. Zhang, M. Polyakov, F. Gibson, M. Chalak, R. Pandit, S. Tapsuwan. 2015. 'Consumers' willingness to pay for renewable energy: A meta-regression analysis." Resource and Energy Economics 42:93-109.

NREL (National Renewable Energy Laboratory). 2018. Top Ten Utility Green Pricing Programs. https://www.nrel.gov/analysis/assets/pdfs/utility-green-power-ranking.pdf. 
NY PSC (New York Public Service Commission). 2016a. Order Authorizing Framework for Community Choice Aggregation Opt-Out Program. Case 14-M-0224.

- 2016b. PSC Establishes Easier Path to Help Residential and Small Business Electricity Consumers Create Power Purchase Associations in New York.

O'Shaughnessy, E., J. Heeter, and J. Sauer. 2018. Status and Trends in the U.S. Voluntary Green Power Market (2017 Data). NREL/TP-6A20-72204. Golden, CO: National Renewable Energy Laboratory.

PG\&E (Pacific Gas \& Electric), and SDG\&E (San Diego Gas \& Electric). 2018. Joint IOU Informal Comments on CPUC's Draft Green Book.

Pichert, D., and K. Katsikopoulos. 2008. "Green Defaults: Information Presentation and ProEnvironmental Behaviour.” Journal of Environmental Psychology 28:63-73.

The Solar Foundation. 2013. Community Choice Aggregation.

Sierra Club. 2018. "100\% Commitments in Cities, Counties and States." https://www.sierraclub.org/ready-for-100/commitments.

Tversky, A., and D. Kahneman. 1991. "Loss Aversion in Riskless Choice: A ReferenceDependent Model.” The Quarterly Journal of Economics 106(4):1039-1061.

Westchester Power. 2018. Annual Report for Calendar Year 2017. 


\section{Appendix. Summary of State CCA Policies, Data, and Key Trends}

This appendix provides a state-by-state summary of policies, trends, and key issues in the eight states with CCA-enabling legislation, as well as an explanation of the data sources behind the statistics presented in the report.

\section{California}

\section{Policy}

In 2002, the California State Legislature passed Assembly Bill 117 allowing the creation of optout CCAs. It allows CCAs to form only in the service territories of the state's investor-owned utilities, covering roughly two-thirds of the state's grid. Customers are automatically enrolled after a minimum of four notifications spanning 120 days but may return to basic utility service at any time, sometimes with a small service fee. Customers opting out after the 120-day enrollment period must remain with the utility for a period of 12 months before they are able to return to CCA service. Gattaciecca, Trumbull, and DeShazo (2017a) provide a comprehensive summary of California CCA policy.

\section{Status}

To date, 18 CCAs are operational in California, with more than half of them launching within the last two years. An additional five CCAs will launch in the coming years, while 8 counties and 11 cities are currently investigating the feasibility of forming a CCA (LEAN Energy U.S. 2018). CCAs, which are expanding rapidly in California, already serve roughly $10 \%$ of California customers and are expected to serve up to $16 \%$ of the state load in 2020 (Gattaciecca, DeShazo, and Trumbull 2018). Looking forward, the three main investor-owned utilities expect $85 \%$ of load departure by 2030 to be due to the launch of new CCAs, the reopening of direct access, energy efficiency, and behind-the-meter generation.

One fundamental characteristic of California CCAs is that they offer their customers multiple products to choose from: often, a default product that is greener than the incumbent utility's basic service and a 100\% renewable energy product. CCAs offer electricity to their communities with renewable energy content ranging from $37 \%$ to $100 \%$, and with a statewide average of $52 \%$ in 2017. In comparison, investor-owned utilities reported producing $32 \%-44 \%$ of their electricity from renewable energy in 2017.

\section{Key Issues}

CCAs in California have indirectly increased the amount of voluntary green power in investorowned utility electricity portfolios. Because investor-owned utilities have renewable energy in long-term contracts, the load departure to CCAs has increased de facto the utilities' renewable energy share over a smaller customer base. The California Public Utility Commission (CPUC) expects investor-owned utilities in California to have collectively over $50 \%$ renewable energy by 2020 (Gattaciecca, DeShazo, and Trumbull 2018).

A key ongoing issue in California is the determination of the Power Charge Indifference Adjustment fee, commonly referred to as an "exit" fee. The exit fee is designed to ensure that customers that leave utilities continue to pay for sunk utility costs, leaving the remaining 
customers financially indifferent to load departure (Gattaciecca, Trumbull, and DeShazo 2017). CPUC is working with all stakeholders to improve the methodology behind the exit fee and to ways to reduce the number of uneconomical contracts in incumbent utility electricity portfolios. We discuss the exit fee in depth in Section 5.7.1.

Competition between CCAs and utilities in California led to the creation of a Code of Conduct in 2012. The code regulates utility interactions with CCAs, including the restriction of marketing and lobbying activities against CCAs. The competitive relationship between CCAs and investorowned utilities also pushed CCAs in California to become more informed and proactive regarding energy procurement, and regulatory and legislative issues than other states (Gattaciecca, Trumbull, and DeShazo 2017a).

Finally, CCAs are required to comply with several pieces of legislation, similar to utilities, including but not limited to the RPS, Senate Bill 350, which sets renewable energy targets and long-term contracting mandates, and resource adequacy requirements. This has led most CCAs that launch with short-term power contracts to increase the proportion of long-term contracts in their electricity portfolio as they mature (Gattaciecca, DeShazo, and Trumbull 2018).

\section{Data}

Default power sales, out-of-state power, and green power sales are calculated using data from the California Energy Commission's Power Source Disclosure ${ }^{24}$ program for each operational CCA in 2017. Data on the number of customers for each CCA were obtained directly from each respective California CCA.

\section{Illinois}

\section{Policy}

Illinois passed legislation to allow the formation of CCAs in 2009 under House Bill 0722. Movein customers are initially enrolled into basic service by default but can be automatically enrolled into CCAs through periodic sweeps. It is unclear whether CCAs are allowed to charge cancellation or reentry fees under the CCA policy. However, according to an interview with Vistra Energy (a competitive supplier), Illinois CCAs are not levying cancellation or reentry fees.

\section{Status}

Illinois remains the largest CCA market in terms of sales, with about 16 million MWh in 2017 , though the market shrunk between 2014 and 2016. About 490 CCAs were active in Illinois as of the end of 2017. The number of active CCAs is rebounding as utility basic service rates increase.

\section{Key Issues}

Illinois CCAs were originally able to offer highly competitive rates with cost savings as high as $\$ 0.03 / \mathrm{kWh}$ (LEAN Energy U.S. 2018) in 2012 and 2013. As a result, CCA sales surged from 2011 to 2013, making Illinois the national CCA leader in terms of sales and customer base. Annual CCA sales peaked at about 25 million MWh in 2014. Annual voluntary green power CCA sales peaked at about 7.8 million MWh in 2013. CCA expansion stalled as the competitive

\footnotetext{
${ }^{24}$ See www.energy.ca.gov/pcl.
} 
edge of CCA rates eroded over time (see Figure 11). Annual CCA sales fell from a peak of about 25 million MWh in 2014 to 16 million MWh in 2017. Voluntary green power sales have fallen even more significantly, from a peak of about 7.8 million MWh in 2013 to 3.5 million MWh in 2017. This shift is driven by changes in basic service rates. The basic service rate fell from an average of $\$ 0.065 / \mathrm{kWh}$ in 2011 to $\$ 0.052 / \mathrm{kWh}$ in 2014 . Some communities chose to disaggregate as CCAs lost their competitive edge. Other communities chose to remain aggregated but dropped the voluntary green power portion of their electricity portfolio in order to reduce costs. The basic service rate has increased steadily since 2014 and Illinois is seeing a resurgence of CCAs, but it is unclear whether CCAs will rebound to 2013-2014 levels.

\section{Data}

The number of projects as of December 2017 (490) is based on the number of CCAs in Municipal Aggregation List with a status of "Supplier Chosen" as of the end of 2017 (ICC 2018a). Default power sales and customers are based on data from ICC (2018a; 2018c). Voluntary green power data are based on data from ICC (2018a) and supply information from Homefield Energy (2018). Additional information on Illinois CCAs was gathered through an interview with Vistra Energy.

\section{Massachusetts}

\section{Policy}

Massachusetts passed CCA-enabling legislation in 1997 under the Utility Restructuring Act. CCAs are prohibited from charging cancellation or reentry fees during an initial 180-day opt-out period. Move-in customers are initially enrolled into basic service before being automatically enrolled into the CCA following an opt-out period. Massachusetts CCAs must be developed in consultation with the Department of Energy Resources and approved by the Department of Public Utilities.

\section{Status}

About 190 CCAs are operational in Massachusetts. Most of them represent single townships; two exceptions are the Cape Light Compact (comprising 21 towns in the Cape Cod area) and Mass CEA (comprising 23 towns in eastern Massachusetts). Most CCAs emphasize customer bill savings rather than voluntary green power procurement (LEAN Energy U.S. 2018). About 35 CCAs in Massachusetts offer voluntary green power. The City of Boston has issued a request for qualifications as a first step toward implementing a CCA with a focus on clean energy integration (Lillian 2018).

\section{Key Issues}

According to interviewees, a key issue facing Massachusetts CCAs is an ongoing debate about retail electricity competition in the state. In 2018, the Massachusetts Attorney General's Office issued a report concluding that retail electricity restructuring has been largely harmful for retail electricity customers (Baldwin 2018). The report concluded that retail electricity customers on competitive supplier service pay higher rates, on average, than customers on basic service, and it recommends the dissolution of the state's competitive retail electricity markets. The report explicitly excludes CCAs, however interviewees expressed concern that the fallout could affect the future of CCAs in the state. 
A second key issue, largely unique to Massachusetts, stems from the fact that the state is split into three load zones: NEMA in northeastern Massachusetts, SEMA in southeastern Massachusetts, and WCMA in western/central Massachusetts. The state's investor-owned utilities serve customers in multiple load zones and are allowed to distribute costs across load zones. In contrast, a CCA situated entirely within a single load zone must recoup costs within that load zone. This situation grants a cost advantage to the utilities under certain conditions. For instance, if capacity costs increase in NEMA, a utility can spread the cost increase across its customers in all three load zones, such that customers in SEMA and WCMA effectively subsidize the customers in NEMA. However, a CCA in NEMA would need to pass the capacity costs through to its customers in NEMA, such that the CCA's customers bear the full capacity cost increase. This type of situation drove the City of Melrose to suspend its CCA in 2017, as rising capacity costs drove all competitive supplier rates above basic service rates.

\section{Data}

Default power results are based on annual CCA filings with the Massachusetts Department of Public Utilities. Voluntary green power data are based on survey data obtained from Cape Light Compact and Colonial Power Group, a supplier for several CCAs in Massachusetts. Other Massachusetts results are based on interviews with Cape Light Compact and Colonial Power Group.

\section{New Jersey}

\section{Policy}

New Jersey passed CCA-enabling legislation in 2002 under the Government Energy Aggregation Act. Unlike other states' legislation, New Jersey's legislation initially called for an opt-in structure, where retail electricity customers would need to opt into rather than out of the CCA. The opt-in structure prevented the emergence of a New Jersey CCA market. Legislative reform removed the opt-in requirements in 2012, and the state's first CCA formed in the same year (LEAN Energy U.S. 2018).

\section{Status}

There are currently about 15 CCAs serving 53 municipalities in New Jersey.

\section{Data}

New Jersey estimates are based on data compiled from three aggregator client lists:

- BGS-Auction: "New Jersey Municipalities with Government Energy Aggregation Programs, July 2017," http://www.bgsauction.com/documents/EDC_Municipal_Aggregation_Programs_July_2017.pdf

- Commercial Utility Consultants: "Client List," https://www.commercialutility.com/clients.html

- New Jersey Aggregation: “Client List,” https://www.njaggregation.us/client_list.html.

Because data were not directly available from New Jersey, survey data and U.S. Census data for Massachusetts were used to estimate CCA participation rates in New Jersey. CCA customers and 
sales were then estimated for New Jersey CCAs based on housing unit information from the U.S. Census and average household electricity use in New Jersey (EIA 2016b).

\section{New York}

\section{Policy}

New York is the most recent state to enact CCA-enabling legislation, passing the legislation in 2014 as part of the state's broader energy policy initiative known as the Reforming the Energy Vision. A subsequent New York Public Service Commission order delineates the state's opt-out provisions (NY PSC 2016a). CCAs must allow for a 30-day opt-out period and are prohibited from charging cancellation fees within the first three billing cycles following CCA implementation. CCAs are required to provide opt-out notices upon contract renewal.

\section{Status}

To date, a single CCA has emerged serving about 855,000 people in Westchester County. The CCA, known as Sustainable Westchester, offers both RPS-compliant and 100\% renewable energy packages. Communities in Oneonta and Onondaga Counties are exploring CCAs. Three additional CCAs were approved by the New York Public Service Commission and at least 50 other communities have passed local laws to form CCAs (Binns 2018). An initiative is underway to explore CCAs in New York City.

\section{Key Issues}

In 2016, the New York Public Service Commission implemented an order allowing cities to gradually phase in a CCA (NY PSC 2016b). The phase-in policy may make CCAs more viable in large cities such as New York, by allowing individual communities within the city to aggregate over time (LEAN Energy U.S. 2018).

\section{Data}

All results are based on data from Westchester Power (2018) and an interview with Sustainable Westchester.

\section{Ohio}

\section{Policy}

Ohio passed CCA-enabling legislation in 1999.

\section{Status}

There are currently around 130 active CCAs in Ohio. The largest is the Northeast Ohio Public Energy Council, which comprises around 220 communities in northeast Ohio. Nearly all Ohio CCAs emphasize cost savings rather than voluntary green power content. The Cities of Cincinnati and Cleveland offer default voluntary green power products.

\section{Key Issues}

CCAs are required to lock into three-year contracts. Due to falling energy prices in Ohio, CCA rates established in fixed-rate three-year contracts become less competitive over time. Some 
CCAs, including the City of Cincinnati's, have responded by negotiating contracts that decline over time in line with projections for declining energy prices.

Customers that move into a CCA community are automatically enrolled into basic service. CCAs in Ohio must conduct periodic sweeps to maintain customer enrollment.

\section{Data}

Data were obtained directly through survey from CCAs in Cincinnati and Cleveland. We estimated an Ohio CCA participation rate by comparing the survey data with housing unit data from the U.S. Census. The remaining communities with CCAs were identified through data from the Ohio Public Utilities Commission. ${ }^{25}$ For these communities, CCA customers and sales were estimated based on the estimated Ohio CCA participation rate and average electricity use in the state of Ohio based on EIA data (EIA 2016b). Some Ohio results are also based on information gathered from an interview with the City of Cincinnati.

\section{Rhode Island}

\section{Policy}

CCAs were first enabled in Rhode Island under the Utility Restructuring Act of 1996. In 1998, the Rhode Island League of Cities and Towns formed the Rhode Island Energy Aggregation Program (REAP), which under RI General Law 45-55-13.2 (1999) was permitted to aggregate electricity and natural gas on behalf of municipalities.

\section{Status}

REAP currently administers a CCA for 32 members, including 28 municipalities, two school districts, and two water supply boards. No CCAs have served residential or small business customers in Rhode Island to date, though doing so is explicitly allowed under the Restructuring Act of 2002 (H 7786). In 2017, H 5536 eliminated a provision requiring individual customers to opt in to aggregation programs and created pathways for opt-out aggregation. Several municipalities have expressed interest in integrating voluntary green power into their CCAs.

\section{Key Issues}

When REAP first began, all participating cities and towns were treated as one unit. REAP administered a single RFP and established a uniform rate for all members. A result of this was that larger municipalities, which would have been able to use economies of scale to procure at lower rates than the uniform rate, were essentially subsidizing rates for smaller municipalities. Over time, REAP allowed more flexibility in member-specific rates and contract terms. Now, cities are able to choose contract lengths of one to three years that are specific to the utilization of each municipality.

While additional flexibility in contract terms helped address the concerns among some participating REAP municipalities, it added complexity that exposed some municipalities to price risk. Some communities locked into relatively high rates by signing contracts in the winter, possibly because of inexperience with electricity markets. Brokers actively promoted their

\footnotetext{
25 "Regulated Company List," Public Utilities Commission of Ohio, https:/www.puco.ohio.gov/puco/index.cfm/docketing/regulated-company-list/?IndId=29
} 
services to municipalities with high locked-in rates, and some municipalities switched to these services without understanding broker fee structures. Moving forward, REAP plans to hire consultants to help cities and towns lock in rates at optimal times.

Passage of HB 5536 in late 2017 removed several procedural hurdles that previously prevented CCAs from serving residential load in Rhode Island. REAP continues to serve municipal and school district aggregations, but cities and counties are beginning to consider CCAs for their residential and business loads.

\section{Data}

Sales and customers estimates are based on data provided by REAP. Some Rhode Island information is based on an interview with REAP.

\section{Virginia}

\section{Policy}

CCAs are allowed under the Virginia Electric Utility Regulation Act $\S 56-589$ on an opt-in or an opt-out basis. CCAs require authorization through a majority vote by the local jurisdiction.

No CCAs have been implemented in Virginia, to date.

\section{Policy Trends in Other Prospective CCA States}

In Section 4.4, we project the potential impacts of CCAs on voluntary green power demand, assuming four additional states pass CCA-enabling legislation: Connecticut, Nevada, New Hampshire, and Oregon. None of these states has taken concrete legislative steps to enable CCAs, to our knowledge; however, their electricity market structures and recent related legislative activity suggest that CCAs could form part of future state policymaking.

Connecticut is a restructured market state, where legislation has been introduced to allow government entities to aggregate their own demand in the past legislative session (S.B. 334, 2018). ${ }^{26}$ In addition, the state has higher-than-average electricity prices for its region, belowaverage customer satisfaction with the primary investor-owned utility (J.D. Power 2017), and high interest in renewables, given the sweeping increase in renewable production standard passed in 2018 (Public Act 18-50). ${ }^{27}$

Nevada currently has energy choice for commercial entities. The state is poised to pass a public ballot initiative requiring the state to restructure its energy market. In addition, customer satisfaction with Nevada Energy is below average (J.D. Power 2017).

New Hampshire is a restructured market state. It has passed legislation to study the feasibility and technical considerations for statewide 100\% renewable energy supply (H.B. 1544, 2018).

\footnotetext{
${ }^{26}$ An Act Concerning Municipal and State Competitive Procurement of Electricity, Natural Gas, Renewable Energy and other Energy-Related Products by Nonprofit Energy Buying Consortia, S.B. 334, Connecticut General Assembly (2018)

${ }^{27}$ An Act Concerning Connecticut's Future, P.A. No. 18-50, Connecticut General Statute (2018)
} 
Oregon is a partially restructured market state allowing choice for commercial entities. In 2017, the state legislative assembly passed S.B. $978,{ }^{28}$ which requires the Oregon Public Utility Commission to investigate emerging industry trends, technologies, and policy drivers. Both this study and further market restructuring could enable the regulatory considerations regarding enabling CCAs. At the same time, there is above-average customer satisfaction with the state's primary investor-owned utilities (J.D. Power 2017), which may dampen community motivation to pursue CCAs. Several cities, however, have expressed interest in customer choice, local control over power supply, and CCAs' economic development potential. CCA legislation is proposed for the 2019 session.

${ }^{28}$ S.B. 978, Oregon Rev. Statute Ch. 741 (2018). 